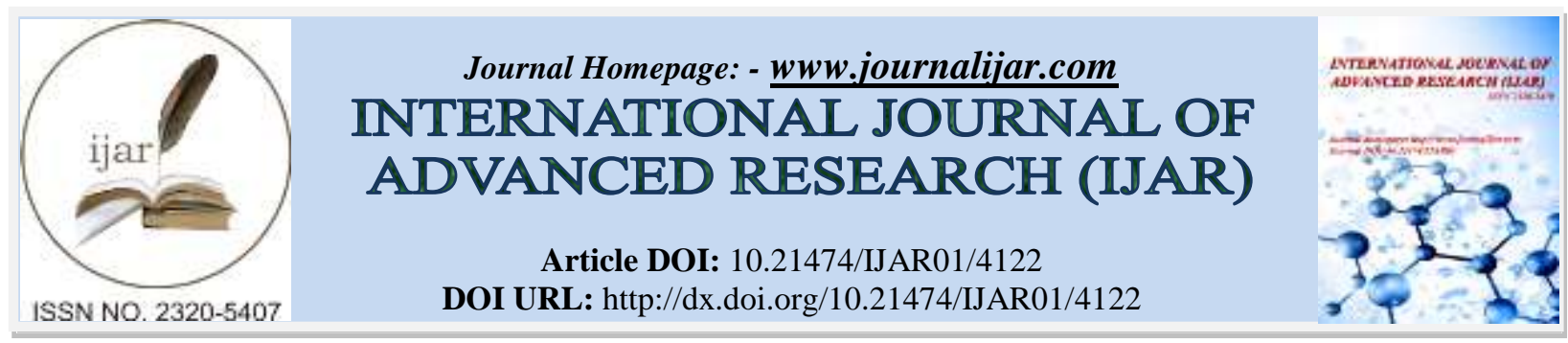

RESEARCH ARTICLE

\title{
PREPARATION AND CHARACTERIZATION OF SHRIMP DERIVED CHITOSAN AND EVALUATION OF ITS EFFICIENCY AS BEE VENOM DELIVERY FOR CANCER TREATMENT.
}

\author{
Fatma. A. Taher ${ }^{1}$, Walaa. A. Moselhy ${ }^{1}$, Aly. F. Mohamed ${ }^{2}$, Samia. E. El-Didamony ${ }^{1}$, Karima. M. Metwalley ${ }^{1}$ \\ and Zayed. A. $\mathbf{B}^{1}$. \\ 1. Faculty of Science, Al-Azhar University (Girls branch). \\ 2. The Holding Company for Production of Vaccines, Sera and Drugs (VACSERA).
}

\section{Manuscript Info}

Manuscript History

Received: 08 March 2017

Final Accepted: 04 April 2017

Published: May 2017

Key words:-

Bee venom, MTT assay, Chitosan nanoparticles, Zeta potenial, DLS, encapsulation efficiency, TEM

\begin{abstract}
Chitosan is an amino polysaccharide prepared by processing shrimp skeleton wastes which involves partial deacetylation of chitin. Many biochemists have found that chitosan as biocompatible, biodegradable and non toxic compound which made wide applicability in conventional pharmaceutics as a potential formulation excipient. The nanoparticles were loaded with venom of Apis mellifera bees and cytotoxicity against colon cancer $(\mathrm{CaCO} 2)$ was evaluated. The crude chitin was collected from exoskeleton of Penaeus kerathurus specimens and was processed to obtain chitosan (CS). Chitosan nanoparticles (CS NPs) were prepared by the ionotropic gelation method of chitosan cations with sodium tripolyphosphate (TPP) anions. The encapsulation efficiency and loading capacity of the bee venom on the prepared chitosan nanoparticles were evaluated. The cytotoxicity of bee venom (BV) alone, chitosan nanoparticles and bee venom loaded chitosan nanoparticles against $\mathrm{CaCo} 2$ cells was conducted using MTT staining assay. Data recorded revealed that the combination of bee venom (BV) with chitosan nanoparticles enhanced the inhibitory effect on colon cancer cells more than treatment with BV alone and chitosan nanoparticles without venom.
\end{abstract}

Copy Right, IJAR, 2017,. All rights reserved.

\section{Introduction:-}

Bee venom (BV) therapy is the therapeutic application for treatment of various diseases. Bee venom has been used as an oriental medicine for the treatment of chronic inflammatory diseases, such as rheumatoid arthritis and pain (Son et al., 2007 and Park et al., 2007). Furthermore, it has been demonstrated that BV inhibits mammary carcinoma cell proliferation in vitro and tumor growth in vivo, such as renal cancer cells (Putz et al., 2007), leukemia cells (Moon $\boldsymbol{e t}$ al., 2009), liver (Wang $\boldsymbol{e t}$ al., 2009), prostate (Park et al., 2011), bladder (Ip et al., 2012) and as well as ovarian (Jo et al., 2012). However, there are a few available studies on the effect of BV on colon cancer cells. Therefore, the present study focused on this cancer type. Colon cancer is one of the major causes of cancer-related deaths in the world. Colon cancer has an estimated incidence of over 1,000,000 new cases annually worldwide. Almost one of three patients with colon cancer dies from the disease. (Janakiram and Rao, 2014 and Swiderska et al., 2014). Present-day nanomedicine exploits carefully a broad variety of structured nanoparticles. These nanoparticles may serve as diagnostic and therapeutic antiviral, antitumor, or anticancer agents (Ghosh $\boldsymbol{e t}$ al. 2008; Faraji et al. 2009; Tiwari et al. 2011; Hu and Zhang 2012). The determinant success in therapeutic and 
diagnostic use of nanoparticle (NP) is the ability to deliver them to desired target. In this sense, NP can be conjugated with biological molecules to make them recognize the biological target. Chitosan a (1-4)-linked 2-amino2-deoxy-b-D-glucopyranose, is derived from chitin, (1-4)-linked2-acetamido-2-deoxy-b-D-glucopyranose. Chitosan can be degraded into $N$-acetyl glucosamine by general lysozymes in the human body, which is subsequently excreted as carbon dioxide via the glycoprotein synthetic pathway. Chitosan is widely used in pharmaceutical and medical purposes due to its advantages and properties such as biodegradability, biocompatibility, low toxicity, haemostatic, bacteriostatic, fungistatic, anticancerogen and anticholesteremic properties (Hejazi \& Amiji 2003). Chitosan has higher positive charge than to other natural polymers; therefore, it is used extensively in drug delivery systems (Dounighi et al., 2010). This work aimed to prepare chitosan nanoparticles and explore the conjugation of BV with chitosan nanoparticles characteristics. The purpose was to enhance the anticancer activity of bee venom, via loading on chitosan nanoparticles.

Materials and Methods:-

Synthesis of chitosan from shrimp exoskeleton:-

Chitosan was extracted from shrimp exoskeleton according to Puvvada et al., 2012, Sewvandi and Adikary, 2012 Patria, 2013, LONG, 2013 and Kamala et al., 2013.

\section{Sample preparation:-}

Abdominal exoskeletons and carapaces that cover the cephalothoracic region of Penaeus karatherus shrimps were removed from the animals and thoroughly washed with running tap water carefully. The shrimp's exoskeletons were subjected to shade drying for 3 consecutive days then placed in oven at $60{ }^{0} \mathrm{C}$ for 24 hrs. The shrimp exoskeletons were crushed into smaller pieces using a meat tenderizer and the dry weights of the carapaces and abdominal exoskeletons samples were determined.

\section{Preconditioning:-}

This step aims to remove loosely bound protein prior to deproteination process. At the preconditioning step, fifty grams of shrimp abdominal exoskeletons and carapaces were soaked in $0.05 \mathrm{M}$ acetic acid solution for 24 hrs. The samples were washed thoroughly with water and then dried in a furnace at $60^{\circ} \mathrm{C}$ for 4 hrs to remove excess water.

\section{Deproteination:-}

The resulted powder of carapaces and abdominal exoskeletons were soaked in 5\% sodium hydroxide solution (1:8 w/v) for two hours under magnetic stirrer at $6{ }^{\circ} \mathrm{C}$ in order to dissolve the proteins and sugars. The mixtures were removed from the magnetic stirrer then allowed to cool for 30 minutes at room temperature. The mixtures were filtered and the residues were washed with distilled water to neutralize $\mathrm{Na} \mathrm{OH}$ effect and re-dried.

\section{Demineralization:-}

The resulted powder was demineralized by soaking in 1\% 0.32-N-hydrochloric acid in the ratio 1:10 (w/v) for $24 \mathrm{hrs}$ to remove the minerals (mainly calcium carbonate). After filtration the residue was washed with distilled water until neutral $\mathrm{pH}$ then dried in a furnace at $60^{\circ} \mathrm{C}$ for $4 \mathrm{hrs}$.

\section{Decolorisation:-}

To remove the natural pigments exists in chitin; acetone was added to chitin residue in the ratio 1:5 (w/v) for $24 \mathrm{hrs}$ at room temperature on a magnetic stirrer. The residue was washed with distilled water and dried. The dry weights of the resulted chitin from both carapaces and abdominal skeleton were determined.

\section{N-deacetylation:-}

$\mathrm{N}$-deacetylation is a process that involves partial removal of acetyl groups from the chitin structure. The deacetylation process was carried out by adding $50 \% \mathrm{NaOH}(1: 10 \mathrm{w} / \mathrm{v})$, using magnetic stirrer at temperatures 90 and $100^{\circ} \mathrm{C}$ for $5 \mathrm{hrs}$. The samples were cooled for $30 \mathrm{~min}$ at room temperature, then washed continuously with distilled water, filtered and dried in order to retain the solid state that represents chitosan. The yield of chitosan was weighed. 


\section{Characterization of the prepared chitosan:- \\ Solubility Test:-}

The acetic acid $1 \%$ was poured to the chitosan at ratio of $0.1 \mathrm{~g}: 100 \mathrm{~mL}$, then it was left at room temperature to dissolve for $24 \mathrm{hrs}$ after that the solubility percent of chitosan samples were determined.

\section{Calculation of deacetylation degree (DDA):-}

Degree of deacetylation of the chitosan was determined by The FT-IR spectrum. Accurate DDA was calculated using Baxter et al., (1992)'s formula:

$\% \mathrm{DDA}=100-\left(\mathrm{A}_{1655} / \mathrm{A}_{3450} \times 115\right)$

Where,

A1655 =Absorption of band at $1655 \mathrm{~cm}-1$

A3450 = Absorption of band at $3450 \mathrm{~cm}-1$

\section{Fourier Transform Infrared (FT-IR) Spectroscopy:-}

The structural features of chitin and chitosan that were extracted from the carapaces (the part of exoskeleton that recorded higher chitosan yield and DDA) were detected by Fourier transform infrared (FTIR- 410® Jasco Colchester, United Kingdom) using Potassium bromide (KBr) pellets.

The pellets of $\mathrm{KBr}$ were placed in an oven at $300^{\circ} \mathrm{C}$ for $24 \mathrm{hrs}$, then mixed with chitin and chitosan in mass ratio 100:

(Bagheri-Khoulenjani $\boldsymbol{e t}$ al., 2009). The mixtures were placed in agate mortar and pressed to tablet form. Three tablets were prepared and dried for 24 hours at $50{ }^{\circ} \mathrm{C}$ in order to remove moisture. The spectra of chitin and chitosan samples were obtained within a frequency range of $\lambda=400-4000 \mathrm{~cm}-1$, each spectrum is an average of 3 scans with a resolution of $2 \mathrm{~cm}-1$.

\section{Determination of viscosity:-}

Intrinsic viscosity was examined using Ubbelohde capillary type viscometer at $25 \pm 1{ }^{\circ} \mathrm{C}$. The measurement was started with the used solvent (acetic acid) and five consecutive values were recorded, then the mean value was calculated. Next, flow times of five different concentrations of chitosan solution were recorded in the same manner. For each chitosan concentration, the following viscosities were determined using the given equation;

Relative viscosity, $\eta \mathrm{rel}=\mathrm{t} / \mathrm{ts}$

Specific viscosity $\eta \mathrm{sp}=(\mathrm{t} / \mathrm{ts})-1$

Reduced viscosity $\eta \mathrm{red}=\eta \mathrm{sp} / \mathrm{C}$

Inherent viscosity, $\eta$ inh $=\ln \eta$ red $/ \mathrm{C}$

Where,

$\mathrm{t}$ means flow time of the used chitosan concentration

ts means flow time of the used solvent

C means the used concentration of chitosan

The reduced viscosity and inherent viscosity were plotted against chitosan concentration. The value of intrinsic viscosity was calculated by extrapolating graph of reduced viscosity and inherent viscosity to zero concentration. The average of the two obtained intercept values was calculated (Yacob et al., 2013)

\section{Determination of molecular weight:-}

Average of chitosan molecular weight was determined by determination of its intrinsic viscosity. The average molecular weight was obtained from Mark-Houwink equation: $\eta=K M a$

Where $\eta$ is the intrinsic viscosity, $\mathrm{M}$ is average molecular weight of the chitosan and $\mathrm{K}$ and a are the Mark-Houwink constants specific for a each polymer. The values of $\mathrm{K}\left(9.66 \times 10-5\left(\mathrm{dm}^{3} / \mathrm{g}\right)\right)$ and a $(0.742)$ for chitosan in acetic acid solution at $25^{\circ} \mathrm{C}$ were determined by Delorino and Cresidio, 2009.

\section{Calculation of ash value:-}

To determine the ash value of chitosan, the method of Monarul et al., 2011 was operated. Two grams of chitosan sample was placed into ignited, cooled, and tarred crucible. The sample was heated in a muffle furnace preheated to $650^{\circ} \mathrm{C}$ for $4 \mathrm{hrs}$. The crucible was allowed to cool in the furnace to less than $200^{\circ} \mathrm{C}$ and then placed into desiccators with a vented top. Percentage of ash value was calculated using the following equation: 


$\boldsymbol{\%} \mathbf{A s h}=\frac{\text { Weight of residue }(\mathrm{g})}{\text { Weight of sample }(\mathrm{g})} \times 100$

Preparation of chitosan nanoparticles and bee Venom cross-linked nanoparticles:-

Chitosan nanoparticles (CS NPs) were prepared mainly by the ionotropic gelation method of chitosan (CS) cations with sodium tripolyphosphate (TPP) anions according to the procedure reported by Rocha Soares et al., 2012 and Dounighi et al., 2012 \& 2015. Chitosan was dissolved in an acetic aqueous solution to prepare different concentrations $(1.0,2.0,3.0,4.0 \& 5.0 \mathrm{mg} / \mathrm{ml})$. The concentration of acetic acid in the aqueous solution was 1.5 folds of chitosan in all cases. Sodium tripolyphosphate (TPP) was dissolved in water obtained by reverse osmosis $(<1.3 \mathrm{mS} / \mathrm{cm})$ at the different concentration (twice, equal, half and quarter) the amount of chitosan. Then drops of TPP solution were added to chitosan solution. Nanoparticles were spontaneously formed by the rapid mixing by homognizer $(\sim 20000 \mathrm{rpm})$ at room temperature for $60 \mathrm{~min}$. to allow complete stabilization of the nanosystem until opalescent suspension obtained. Finally nanoparticles were separated by centrifuge at $11000 \mathrm{rpm}$ and $4{ }^{\circ} \mathrm{C}$ for 90 min; lyophilized then stored at $4^{\circ} \mathrm{C}$. The bee venom-loaded nanoparticles were formed by the addition of various concentrations of venom $(10,50,100,200,300 \& 500 \mu \mathrm{g} / \mathrm{ml})$ to TPP solution prior to the incorporation of chitosan solution. In order to evaluate one factor (chitosan concentration, TPP concentration or bee venom concentration, its own concentration was changed and the two other factor concentration remained constant.

\section{Physicochemical and biological characterization of nanoparticles:- Determination of encapsulation efficiency and loading capacity:-}

The amount of venom encapsulated in the nanoparticles was measured by calculating the difference between the total amounts of the venom added in the nanoparticle preparation solution and the amount of non entrapped venom remaining in the clear supernatant which evaluated by (Bradford, 1976) method at 595nm after the centrifugation of samples at $11,000 \mathrm{rpm}$ and $4^{\circ} \mathrm{C}$ for $90 \mathrm{~min}$. After that the venom encapsulation efficiency (AE) of nanoparticles and loading capacity (LC) were calculated as follows:

$\% \mathrm{AE}=[(\mathrm{A}-\mathrm{B}) / \mathrm{A}] \times 100$

$\% \mathrm{LC}=[(\mathrm{A}-\mathrm{B}) / \mathrm{C}] \times 100$

Where $\mathrm{A}$ is the total amount of venom, $\mathrm{B}$ is the free amount of venom and $\mathrm{C}$ is the weight of nanoparticles.

\section{Determination of the particle size and zeta potential:-}

The average particle size and size distribution [polydispersity index (PDI) of particles were evaluated by Zetasizer (Malvern Instruments, UK), based on the dynamic light scattering (DLS) technique. Particle size was reported on the basis of Number mean diameter (NMD). The zeta potential was measured by the same instrument, based on an electrophoretic light scattering (ELS) technique for fresh prepared nanoparticles, after two and four months of incubation at room temperature.

\section{Fourier Transform Infrared (FT-IR) Spectroscopy:-}

The structural features of free chitosan nanoparticles and bee venom loaded chitosan nanoparticles were estimated by FTIR as was described before.

\section{Transmission electron microscopy:-}

The morphology of free chitosan nanoparticles and bee venom loaded chitosan nanoparticles were investigated by transmission electron microscope (TEM) in the National Research Center, Giza, Egypt. The samples were fixed on copper grids, stained with $1 \%$ phosphotungstic acid solution (PTA). The specimens were air-dried at room temperature and examined using Philips 400 transmission electron microscope (Netherlands) at an accelerating voltage of $80 \mathrm{kV}$.

In vitro release study:-

Different tubes containing $3 \mathrm{mg}$ of freeze dried nanoparticles and $3 \mathrm{ml}$ of $0.2 \mathrm{~mol} / \mathrm{L}$ phosphate buffer (PBS) solution (pH 7.4) were incubated with shaking at $37^{\circ} \mathrm{C}$ and $200 \mathrm{rpm}$.

A single tube was removed at appropriate time intervals (1, 2, 4, 6, 17, 24, 30 and 48 hours) and centrifuged at $11,000 \mathrm{rpm}$ and $4^{\circ} \mathrm{C}$ for 30 minutes. The amount of venom released in the supernatant was measured by the 
Bradford protein assay spectrophotometric (Bradford, 1976) method at $595 \mathrm{~nm}$. Triplicate samples were analyzed and the total released protein concentration at each time was calculated from a standard curve (Fig. 1) as follows

Concentration of drug $=$

(Absorbance - Intercept)

Amount of drug released $=$

Slope

Concentration $\times$ total volume of release media $\times$ dilution factor

Where, Dilution factor $=10$

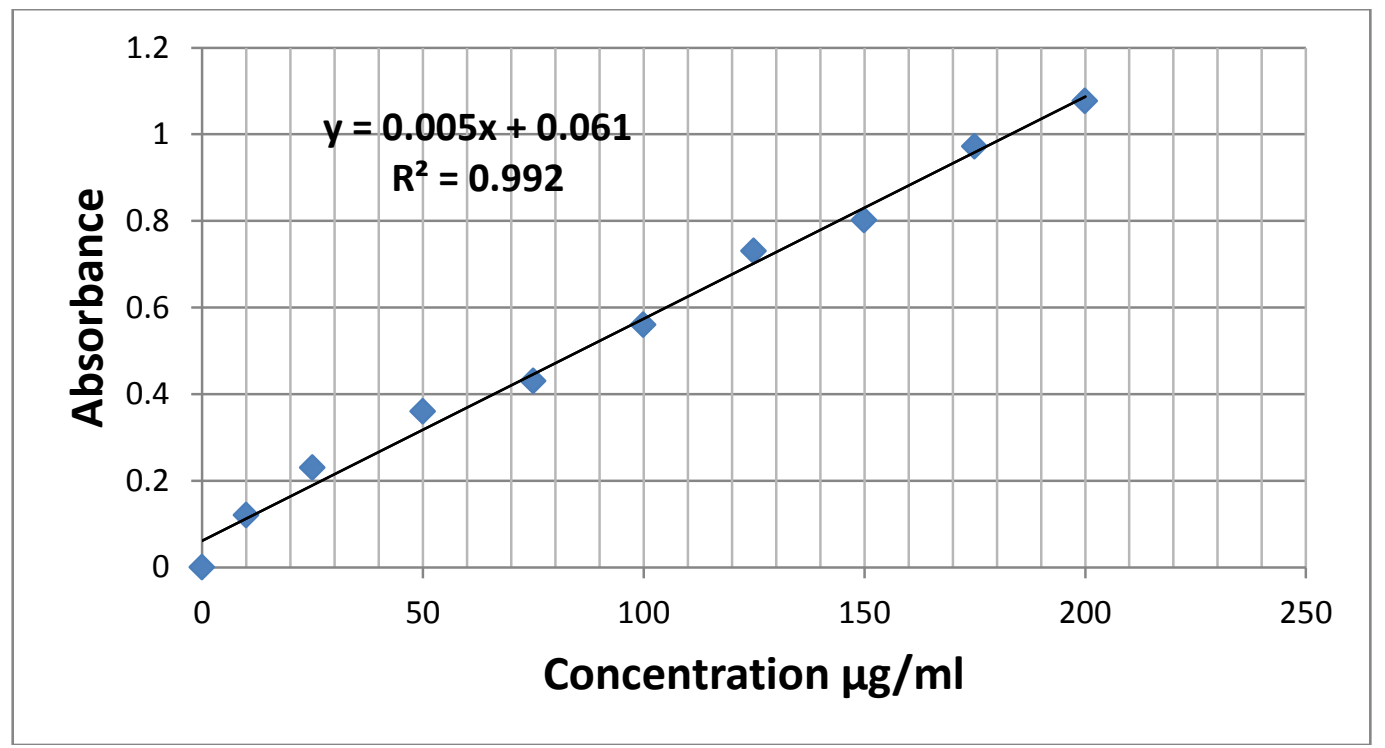

Figure 1:- Standard curve for determination of unknown protein concentration

Cytotoxicity assay:-

Colon cancer $(\mathrm{CaCo} 2)$ cells were seeded in 96 well tissue culture micro titer plates (Nunc-Denmark), RPMI-164 growth medium (Gibco BRL, Grand Island, NY) and supplemented with $10 \%$ fetal bovine serum (FBS), $1 \mathrm{mM}$ sodium pyruvate, $2 \mathrm{mM} \mathrm{L}$-glutamine and antibiotics (penicillin $100 \mathrm{IU} / \mathrm{ml}$, streptomycin $100 \mu \mathrm{g} / \mathrm{ml}$ ). Plates were incubated at $37^{\circ} \mathrm{C}$ for 24 hours. Media was decanted, the cells were treated with the different test materials. Bee Venom was added to the cells at concentrations $400,200,100,50,25,12.5,6.25,3.125,1.6$ and $0.8 \mu \mathrm{g} / \mathrm{mL}$, chitosan nanocapsulated bee venom was used at concentrations $300,150,75,37.5,18.75,9.37$ and $4.68 \mu \mathrm{g} / \mathrm{ml}$ and chitosan nanoparticles at $1 \mathrm{mg} / \mathrm{ml}$ final concentration. equal volumes of media were added to cells as control as $100 \mu \mathrm{l} /$ well. Plates were incubated at $37^{\circ} \mathrm{C}$, and $5 \% \mathrm{CO}_{2}$ atmospheric conditions for $24 \mathrm{~h}$ in case of treatment with bee venom alone and $48 \mathrm{~h}$ in both nanoparticles treatments to permit the release of bee venom from nanoparticles encapsulation. After that the media were removed, and plates were washed with phosphate-buffered saline (PBS) and the cells were incubated with 50 $\mu 1 /$ well of (3-(4, 5-Dimethylthiazol-2-yl)-2, 5-di tetrazolium bromide (MTT) solution. After incubated for $4 \mathrm{~h}$ at $37^{\circ} \mathrm{C}$ and $5 \% \mathrm{CO}_{2}$, DMSO or $0.04 \%$ acidified Isopropanol solution was added as $0.05 \mathrm{ml} /$ well. Finally, the absorbance of each well was read at a wavelength $570 \mathrm{~nm}$ using ELIZA reader. The viability percent was calculated as follows:

Viability \% = Mean OD Treated X 100 / Mean OD Control.

Where,

OD is optical density

The $\mathrm{IC}_{50}$ is the concentration of used drug or material required to induce $50 \%$ inhibition of cell growth and the value was calculated by fitting the survival curve using graph pad, prism software in corporate (Gerlier and Thomasset, 1986). 


\section{Results:-}

The yield of extracted chitin and chitosan:-

The chitin yield from $50 \mathrm{gm}$ abdominal exoskeletons and carapaces were $43.95 \%$ and $48.41 \%$, respectively. After $\mathrm{N}$-deacetylation, the chitosan yield from chitin of abdominal exoskeleton and carapace samples were $54.94 \%$ and $59.60 \%$, respectively.

\section{Characterization of the prepared chitosan:-}

\section{Solubility Test:-}

The solubility of chitosan is one of important parameter for quality of chitosan, where the better chitosan show a higher solubility. Data revealed that the solubility percentage of chitosan extracted from abdominal skeletons and carapaces at the same conditions were $91.17 \%$ and $100 \%$, respectively.

\section{Degree of deacetylation (DDA):-}

Degree of deacetylation affects the chemical, physical and biological properties of chitosan, such as adsorption, covalent linking, encapsulation. The DDA of chitosan sample prepared from carapaces of Penaeus karatherus was $84.71 \%$. This percentage was lower in chitosan sample prepared from abdominal skeleton at the same conditions $(80.29 \%)$.

\section{Fourier Transform Infrared (FT-IR) Spectroscopy:-}

The structure of chitin and chitosan extracted from carapace of Penaeus karatherus shrimp was investigated by FTIR spectroscopy, as shown in [Fig. 2 and tab. 1].

[Fig.2] illustrated the FT-IR spectrum of chitin which revealed that the peak $3437 \mathrm{~cm}-1$ indicates the presence of $\mathrm{OH}$ stretching coupled and showed an intense peak at $1564 \mathrm{~cm}-1$ which correspond to the N-H deformation of amide II. The band at $1655 \mathrm{~cm}-1$ corresponds to the amide I stretching of $\mathrm{C}=\mathrm{O}$ group. The wave number $2929 \mathrm{~cm}-$ 1is characteristic of asymmetrical stretching of $\mathrm{CH} 2$, whereas $2522 \mathrm{~cm}-1,1066 \mathrm{~cm}-1$ and $743 \mathrm{~cm}-1$ position of the spectrums are the characteristic $\mathrm{CH}$ stretching, $\mathrm{CO}$ and skeletal stretch respectively, These asymmetrical stretching, bending and skeletal stretch confirm the presence of the chitin [Tab.1].

The IR spectrum of chitosan polymer showed peaks assigned to the polysaccharide structure at $1154,1077,1033$, and $896 \mathrm{~cm}-1$, where the major absorption band was observed at peak $1033 \mathrm{~cm}-1$ which represents the free amino group (-NH2) at $\mathrm{C} 2$ position of glucosamine, a major group present in chitosan. The peak at $1382 \mathrm{~cm}-1$ represents the $-\mathrm{C}-\mathrm{O}$ stretching of primary alcoholic group $(-\mathrm{CH} 2-\mathrm{OH})$ and The peak at $1643 \mathrm{~cm}-1$ corresponds to the amide I stretching of $\mathrm{C}=\mathrm{O}$ group. The peak at $1427 \mathrm{~cm}-1$ was the joint contribution of bend vibration of $\mathrm{OH}$ and $\mathrm{CH}$ [Fig.2 and tab.1].

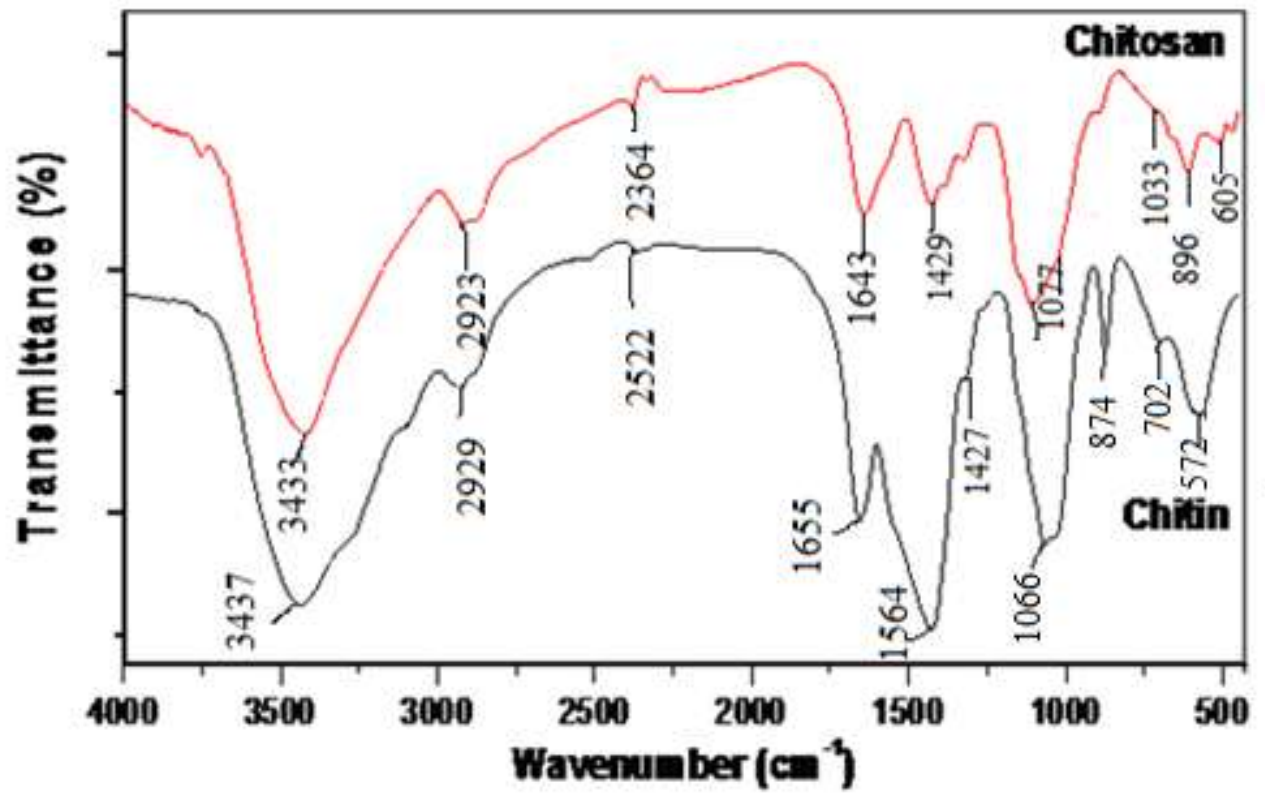

Fig. (2):- FT-IR spectrum of extracted chitin and Chitosan from Penaeus karatherus shrimp carapaces 
Table (1). Wavelength of the main bands obtained for extracted Chitin and chitosan from Penaeus karatherus carapaces.

\begin{tabular}{l|cc}
\multicolumn{1}{c|}{ Vibration modes } & Wavelength of bands (cm-1) \\
& Chitin & chitosan \\
NH out - of- plane bending & 702 & 605 \\
\hline Ring stretching & 874 & 896 \\
\hline CO stretching & 1066 & 1077 \\
NH2 the free amino group & - & 1033 \\
$\mathrm{CH} 2$ bending and CH3 de formation & 1427 & 1427 \\
Amide II band $\quad 1564$ & - \\
Amide I band & 1655 & 1643 \\
\hline CH stretching & 2522 & 2364 \\
\hline Symmetric CH3 stretching and asymmetric $\mathrm{CH} 2$ & 2929 & 2923 \\
stretching & 3437 & 3433 \\
OH stretching & & \\
\hline
\end{tabular}

\section{Determination of viscosity:-}

The intrinsic viscosity was determined for the chitosan that was extracted from carapaces of Penaeus karatherus shrimps because it had the optimum DDA. The intrinsic viscosity of chitosan obtained in this study was $147.6 \mathrm{CPas}$ (Tab. 2).

Determination of molecular weight:-

The molecular weight of chitosan is one parameter that can be used as a standard for quality. Average molecular weight of chitosan was obtained via viscosity measurement.

Results in tab. (2) revealed that the chitosan which extracted from carapaces of Penaeus karatherus shrimps had low molecular weight, $11526.93 \mathrm{Da}$.

Calculation of ash value:-

In the present study chitosan obtained from carapaces of Penaeus karatherus shrimps had very low ash value that was $0.4 \%$ [Tab. 2].

Table (2). Characteristics of extracted chitosan from the Penaeus karatherus carapace

\begin{tabular}{|lc|}
\hline \multicolumn{1}{|c|}{ Characteristics } & Chitosan \\
\hline Chitosan yield & $59.60 \%$ \\
\hline Solubility & $98.75 \%$ \\
\hline Degree of deacetylation & $84.71 \%$ \\
Viscosity & 147.6 cpas \\
\hline Average molecular weight & $11526.93 \mathrm{Da}$ \\
Ash value & $0.4 \%$ \\
\hline
\end{tabular}


Physicochemical and biological characterization of the prepared chitosan nanoparticles:-

The bee venom loaded CS NPs instantaneously formed, when solution of polyanionic TPP and bee venom was added to the CS solution.

\section{Determination of encapsulation efficiency and loading capacity:-}

The present study investigated the effect of changing the chitosan concentrations, bee venom concentrations and TPP concentrations on the encapsulation efficiency and loading capacity of bee venom on nanoparticles, while one factor was tested, the other two factors remained constant (Figs. 3, 4 \& 5).

[Fig. 3] showed that the change of encapsulation efficiency due to increasing of chitosan concentration had two phases. Phase (1): increasing of chitosan concentration from 1.0 to $3.0 \mathrm{mg} / \mathrm{ml}$ increased encapsulation efficiency slightly from $91.58 \%$ to $92.78 \%$. Phase (2): increasing of chitosan concentration from 3.0 to $5.0 \mathrm{mg} / \mathrm{ml} \mathrm{decreased}$ encapsulation efficiency from $92.78 \%$ to $70.04 \%$. Whereas, loading capacity was decreased gradually from $8.64 \%$ to $1.34 \%$ with increasing of chitosan concentration from 1.0 to $5.0 \mathrm{mg} / \mathrm{ml}$.

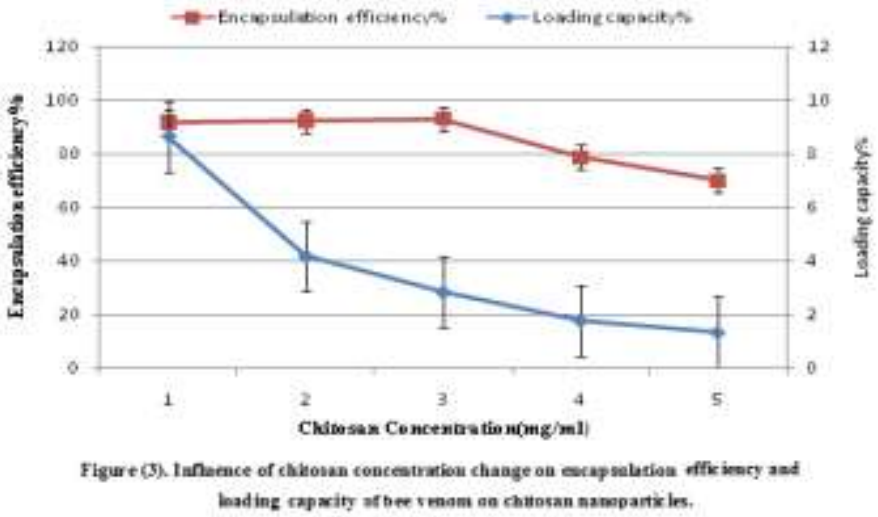

The effect of bee venom concentration $(10,50,100,200,300 \& 500 \mu \mathrm{g} / \mathrm{ml})$ change on encapsulation efficiency and loading capacity was represented in fig. 4. Data revealed that, increasing of the venom concentration from 10 to $500 \mu \mathrm{g} / \mathrm{ml}$, both \% encapsulation efficiency and \% loading capacity increased. Encapsulation efficiency values raised from $86 \%$ to $96.55 \%$, while loading capacity elevated from $0.81 \%$ to $45.54 \%$.

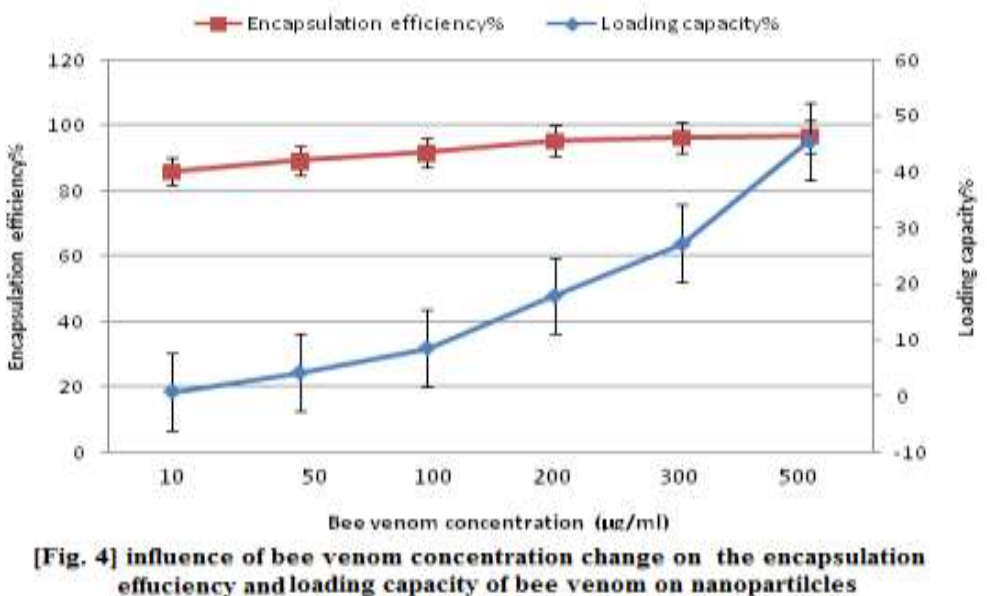

As shown in fig. 5, the encapsulation efficiency was gradually increased $(76.75 \%$ to93.20\%, ) relatively to TPP concentration $(0.5,1,2 \& 3 \mathrm{mg} / \mathrm{ml})$ while there was a slight elevated loading capacity $(3.48 \%-4.23 \%$. 


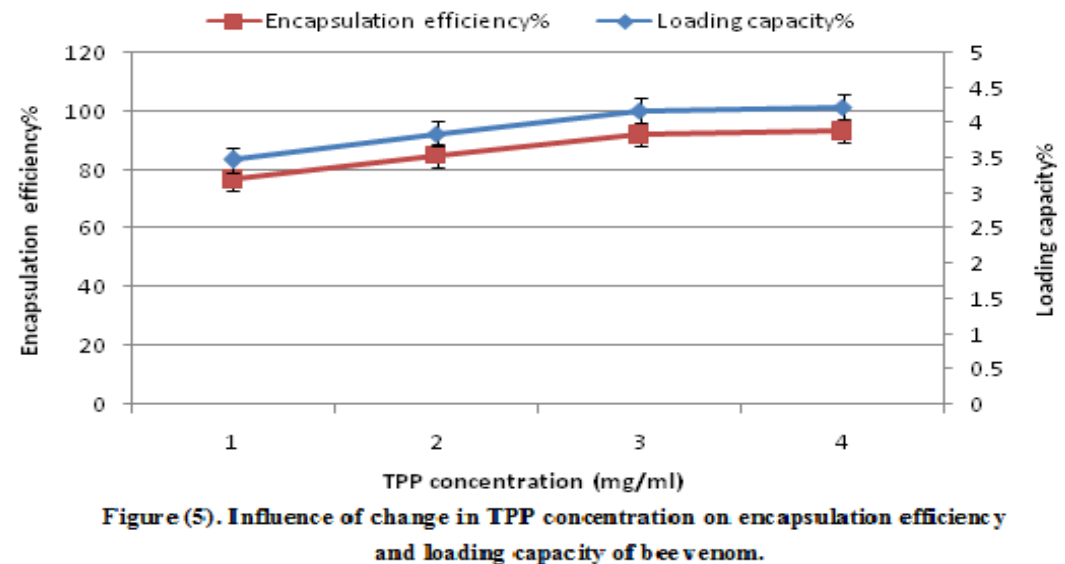

\section{Determination of the particle size:-}

The data in tab. 3 revealed that by increasing the chitosan concentration from 1 to $5 \mathrm{mg} / \mathrm{mL}$ at a constant TPP concentration and zero concentration of bee venom, the size of nanoparticles significantly increased from $140.3 \mathrm{~nm}$ to $505.3 \mathrm{~nm}$. Also, the results indicated that the venom-loaded nanoparticles are larger than the chitosan-TPP ones, (Figs. 6\&7). The nanoparticle which prepared by cconcentration of chitosan $1 \mathrm{mg} / \mathrm{ml}$ have a smaller size and better polydispersity index.

Tab. 3:- Effect of change in chitosan concentration on particle size and polydispersity index of nanoparticles.

\begin{tabular}{|l|l|l|}
\hline Chitosan concentration $\mathbf{( m g} / \mathbf{m l})$ & Particle size(nm) & Polydispersity index (PDI) \\
\hline 1.0 & 140.3 & 0.421 \\
\hline 2.0 & 198.2 & 0.397 \\
\hline 3.0 & 290.0 & 0.565 \\
\hline 4.0 & 476.3 & 0.923 \\
\hline 5.0 & 505.3 & 0.457 \\
\hline
\end{tabular}

$\begin{array}{rlllll} & & \text { Size (d.nm): } & \% \text { Number } & \text { Width (d.nm... } \\ \text { Z-Average (d.nm): } & 313.1 & \text { Peak 1: } & 140.3 & 100.0 & 74.35 \\ \text { Pdl: } & 0.421 & \text { Peak 2: } & 0.000 & 0.0 & 0.000 \\ \text { Intercept: } & 0.888 & \text { Peak 3: } & 0.000 & 0.0 & 0.000\end{array}$

Result quality : Refer to quality report

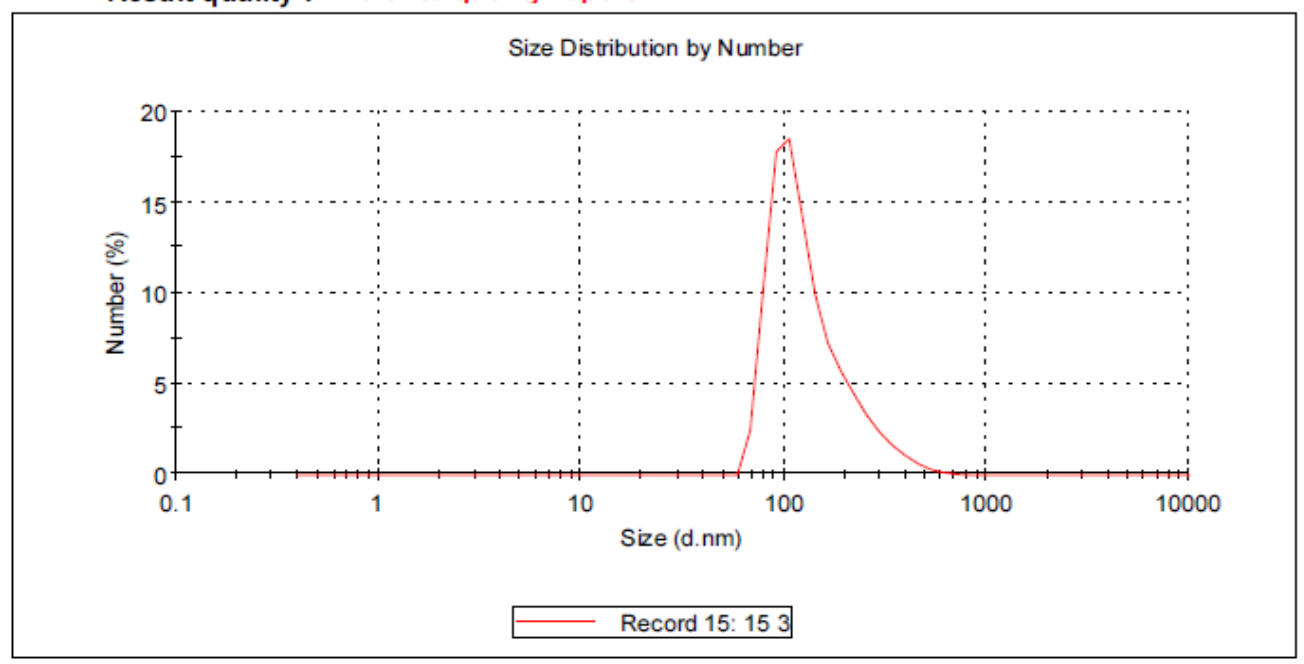

Fig. 6:- Size distribution by number of free chitosan nanoparticles (Chitosan $1 \mathrm{mg} / \mathrm{ml}$ and TPP $1 \mathrm{mg} / \mathrm{ml}$ ). 


$\begin{array}{rlllll} & & & \text { Size (d.nm): } & \% \text { Number } & \text { Width (d.nm... } \\ \text { Z-Average (d.nm): } & 298.5 & \text { Peak 1: } & 187.7 & 100.0 & 64.20 \\ \text { Pdl: } & 0.391 & \text { Peak 2: } & 0.000 & 0.0 & 0.000 \\ \text { Intercept: } & 0.915 & \text { Peak 3: } & 0.000 & 0.0 & 0.000 \\ \text { Result quality : } & \text { Refer to quality report } & & & \end{array}$

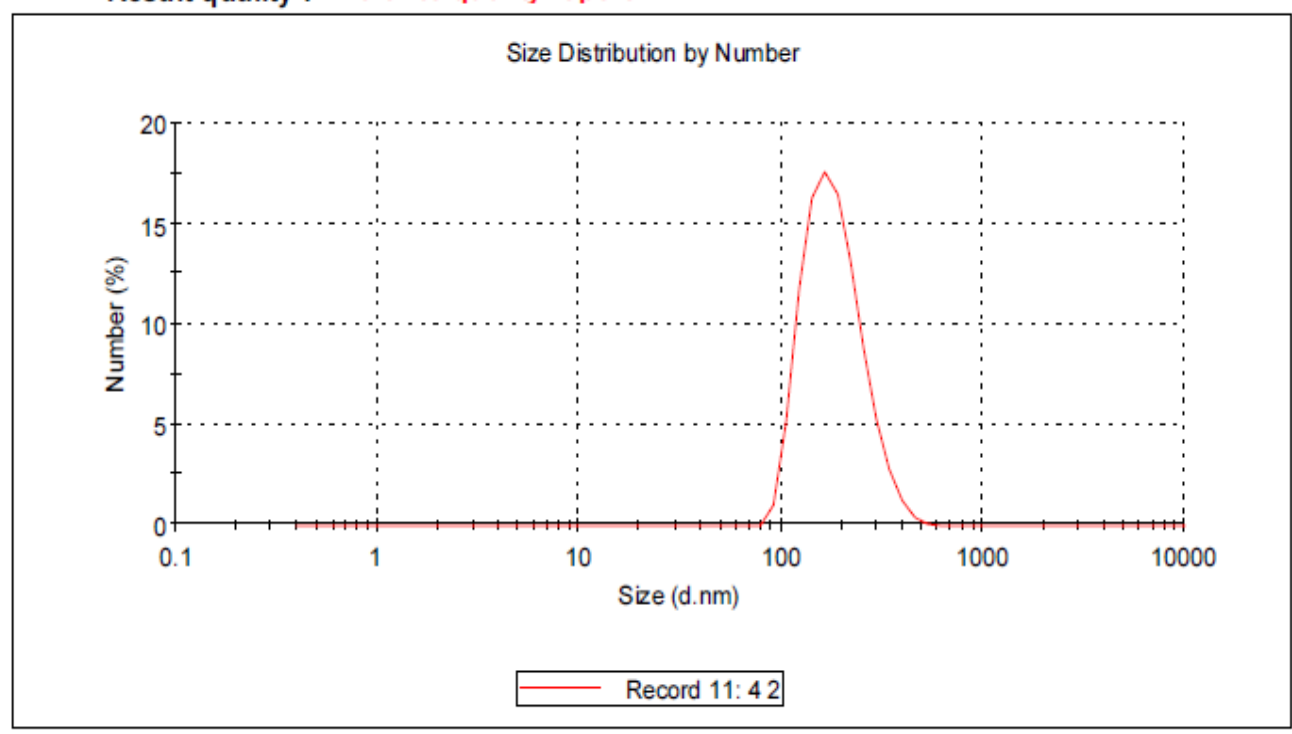

Fig. 7:- Size distribution by number of Apis mellifera venom-loaded chitosan-TPP nanoparticles (chitosan: 1 $\mathrm{mg} / \mathrm{mL}$; TPP: $1 \mathrm{mg} / \mathrm{ml}$ and Apis mellifera venom $(300 \mu \mathrm{g} / \mathrm{mL})$

\section{Determination of zeta potential:-}

Data in tab. (4) illustrated zeta potentials of chitosan nanoparticles and venom-loaded chitosan nanoparticles those were prepared at optimum concentrations $(1 \mathrm{mg} / \mathrm{ml} \mathrm{CS}$ with $300 \mu \mathrm{g} / \mathrm{ml}$ of venom) with encapsulation efficiency of $96.26 \%$ and loading capacity of $28.87 \%$. The values of zeta potentials were 43.7 and $36.1 \mathrm{mV}$ of chitosan nanoparticles and fresh prepared venom-loaded chitosan nanoparticles, respectively. These results demonstrated that the venom loading leads to a minor reduction of the particle's zeta potential. Zeta potential slightly reduced to 35.5 and $35 \mathrm{mv}$ after two and four months of incubation, respectively at accelerated stability test condition.

Tab. 4:- Zeta potential of chitosan nanoparticles, Apis mellifera venom loaded chitosan nanoparticles at the beginning of preparation, after two and four months of incubation.

\begin{tabular}{|l|c|}
\hline \multicolumn{1}{|c|}{ Samples } & Zeta potentials (mV) \\
\hline Chitosan nanoparticles & $\mathbf{4 3 . 7}$ \\
\hline Fresh prepared bee venom loaded chitosan nanoparticles & $\mathbf{3 6 . 1}$ \\
\hline Bee venom loaded chitosan nanoparticles a two months post incubation & $\mathbf{3 5 . 5}$ \\
\hline Bee venom loaded chitosan nanoparticles four months post incubation & $\mathbf{3 5 . 0}$ \\
\hline
\end{tabular}

\section{Fourier Transform Infrared (FT-IR) Spectroscopy:-}

The ability of the ionic gelation process to form venom-loaded chitosan nanoparticles was assessed by employing FTIR to determine venom-chitosan interactions. The FTIR spectra of chitosan, chitosan nanoparticles and venom loaded chitosan nanoparticles were shown in fig. (8). In the chitosan spectra the strong peak in the range of 3200$3400 \mathrm{~cm}-1$ ranges corresponds to combined peaks of $\mathrm{O}-\mathrm{H}$ stretching and intermolecular hydrogen bonding. The $\mathrm{N}-$ $\mathrm{H}$ stretching from primary amines were overlapped in the same region. The absorption band of the carbonyl $(\mathrm{C}=\mathrm{O})$ stretching of the secondary amide (amide I band) was shown at $1643 \mathrm{~cm}-1$ and peak at $1077 \mathrm{~cm}-1 \mathrm{belongs}$ to the C$\mathrm{O}-\mathrm{C}$ stretching. The spectrum of chitosan nanoparticles was differ from that of chitosan matrix. In chitosan nanoparticles the peak of $3432 \mathrm{~cm}^{-1}$ became wider with increased relative intensity indicating an enhancement of hydrogen bonding. Also, the $1643 \mathrm{~cm}^{-1}$ peak of - NH2 bending vibration shifted to $1537 \mathrm{~cm}^{-1}$ and a new sharp 
peak $1639 \mathrm{~cm}-1$ appears. The cross linked chitosan also showed a $\mathrm{P}=\mathrm{O}$ peak at $1170 \mathrm{~cm}-1$. The spectrum of venom loaded chitosan nanoparticles did not show any changes as compared with the spectrum of chitosan nanoparticles.

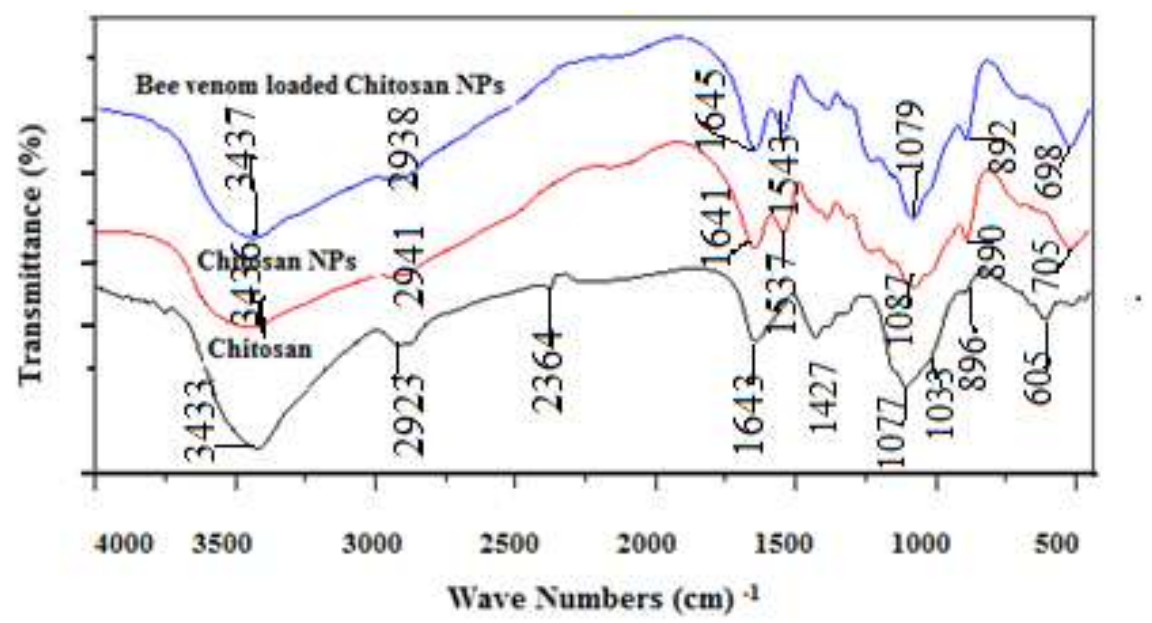

Figure[8]. FTIR Spectra of Chitosan matrix, Chitosan Nanoparticles and Apis Millifera bee venom loaded chitosan nanoparticles

\section{Transmission electron microscopy:-}

Transmission electron microscope (HR-TEM) micrographs of chitosan nanoparticles and bee venom-loaded chitosan nanoparticles were prepared at optimum concentrations $(1 \mathrm{mg} / \mathrm{ml}$ CS and $1 \mathrm{mg} / \mathrm{ml}$ TPP for chitosan nanoparticles and $1 \mathrm{mg} / \mathrm{ml} \mathrm{CS}$ and $1 \mathrm{mg} / \mathrm{ml}$ TPP with $300 \mu \mathrm{g} / \mathrm{ml}$ of venom) with encapsulation efficiency of 96.26 and particle size of 140 and $187 \mathrm{~nm}$, respectively [Fig.9]. The nanoparticles had nearly spherical shape with smooth surfaces. Also, results showed that bee venom formed a layer around the nanoparticles core which was observed by phospho-tungestic acid staining and increased the hydrodynamic size of bee venom-capped chitosan nanoparticles.

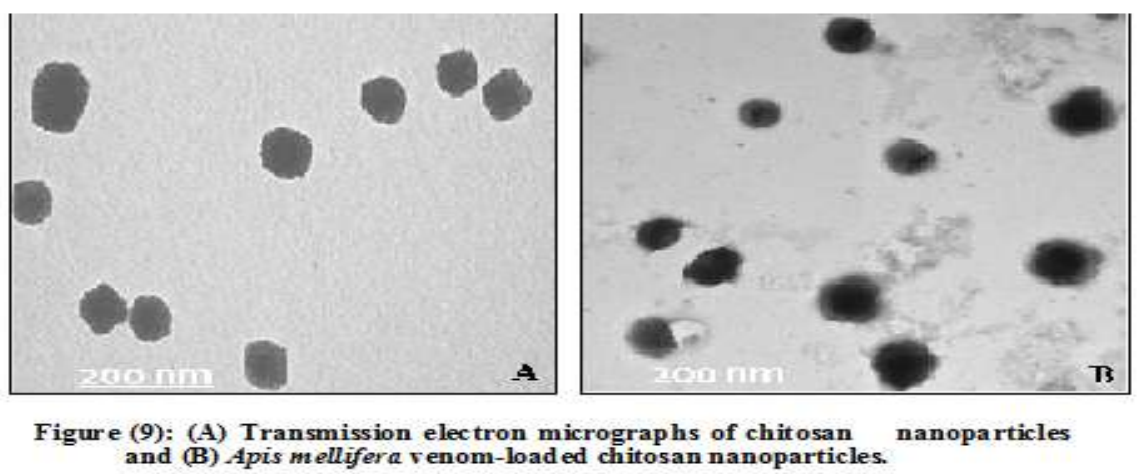

In vitro release study:-

In vitro release of the venom loaded CS NPs was evaluated using the NPs that were prepared at the optimum concentrations with encapsulation efficiency of 96.26 and loading capacity of $28.87 \%$. The release behavior was shown in [Fig.10]. Data showed that about $85 \%$ of the loaded venom was released within 48 hours of incubation in phosphate buffer solution (PBS), $\mathrm{pH} 7.4 \pm 0.2$. The venom release profile exhibited an initial burst release of about $50 \%$ in the first 6 hours followed by a slow release of $35 \%$ for the subsequent $42 \mathrm{hrs}$. 


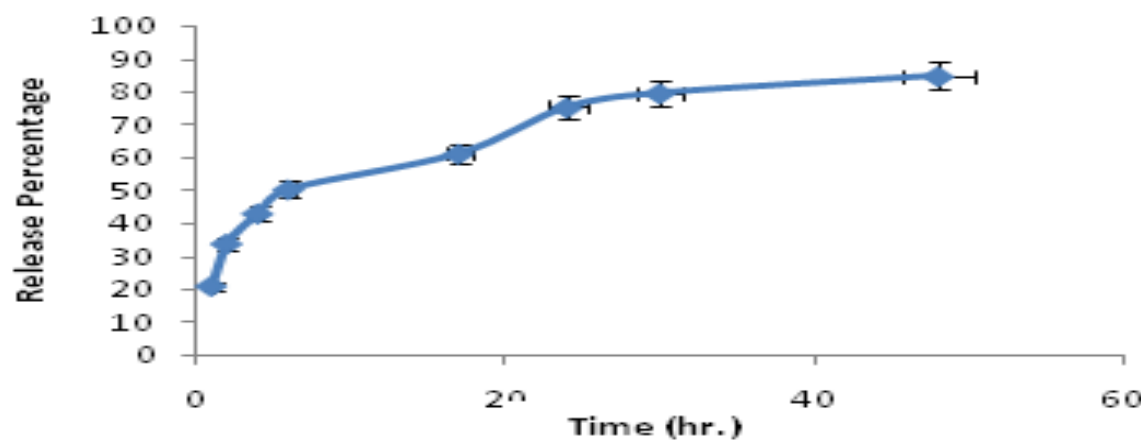

[Fig. 10]. Release profile of Apis mellifera venom from

Chitosan nanoparticles relative to time.

\section{Cytotoxicity assay:-}

The inhibitory effect of bee venom, chitosan nanoparticles and bee venom chitosan nanoparticles on cell growth of colon cancer was assessed by MTT assay. Bee venom alone significantly inhibited the growth of human colon cancer cells compared with the control cells in a dose - dependent manner. The combination of bee venom with chitosan nanoparticles enhanced the effect of bee venom on the cancer cells proliferation, where the inhibitory concentration $\left(\mathrm{IC}_{50}\right)$ of bee venom was $8.5 \mu \mathrm{g} / \mathrm{ml}$ and was $6.9 \mu \mathrm{g} / \mathrm{ml}$ in vase of bee venom loaded chitosan nanoparticles. Also, data recorded in showed that chitosan nanoparticles recorded the lowest inhibitory effect on the viability of tested cancer cell line compared with bee venom and venom loaded nanoparticles that, $\mathrm{IC}_{50}$ value was $135.7 \mu \mathrm{g} / \mathrm{ml}$ [Fig. 11].
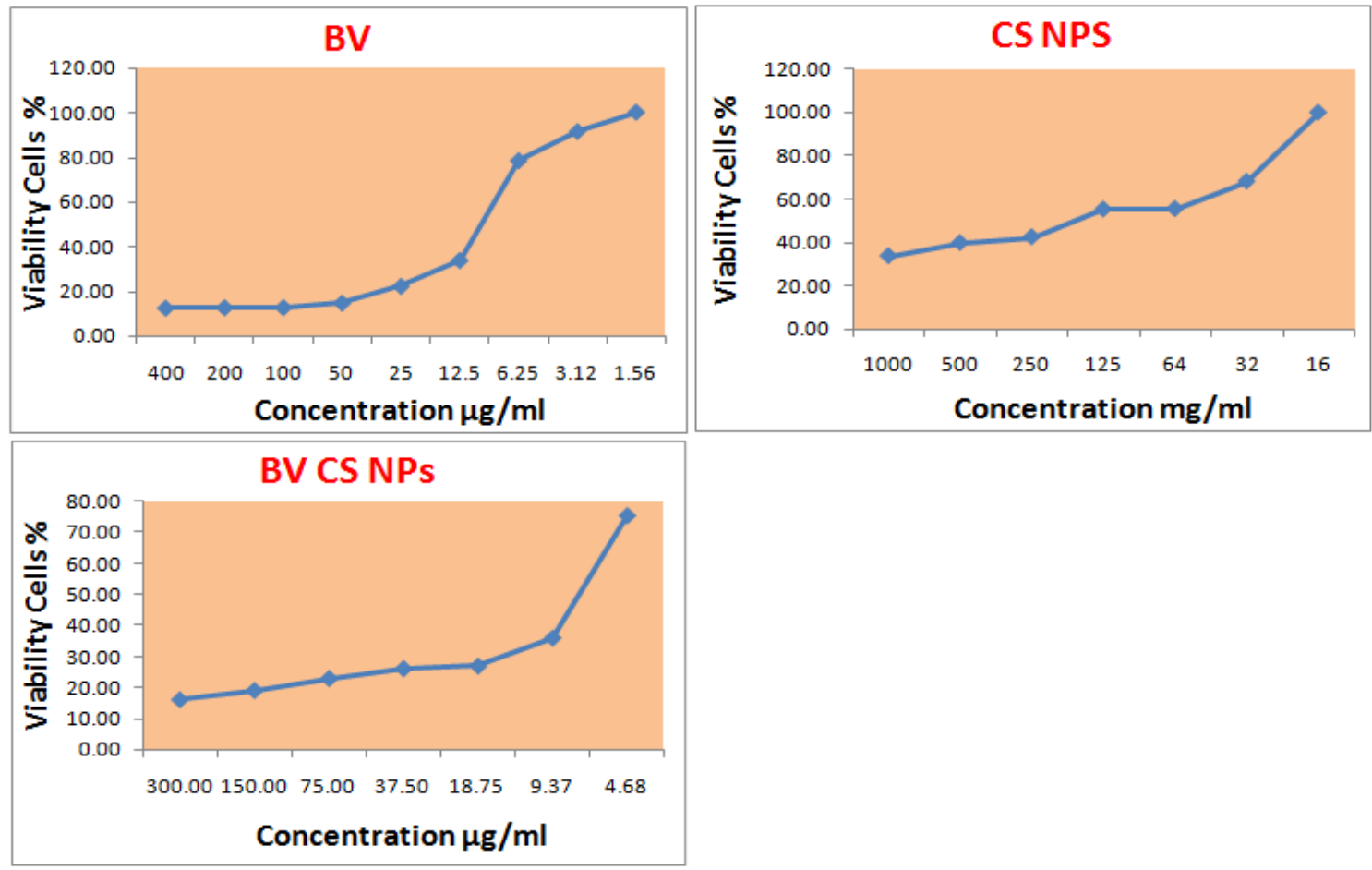

Fig. 11:- Relationship between bee venom, chitosan nanoparticles and bee venom loaded chitosan nanoparticles concentrations and viability percentage of colon cancer cells.

\section{Morphological observation:-}

In the present study, the morphology of the treated colon cancer cells and control cells were investigated under inverted microscope [Fig.12]. 
Untreated cells were well adherent, homogeneously distributed in the culture field exhibiting a polygonal shape with distinct boundaries and homogenous cellular contents. On the other hand, the treatment of cancer cells with the higher concentrations of bee venom, chitosan nanoparticles and bee venom loaded chitosan nanoparticles resulted in destruction of cell sheet, cell shrinkage, rupturing and detaching from the surface of tissue culture. At the low concentrations of bee venom, chitosan nanoparticles and bee venom loaded chitosan nanoparticles some of the treated cells lost their characteristic appearance, changed into small round single cells and detached out of the culture surface, while other cells retained their normal morphological appearance.
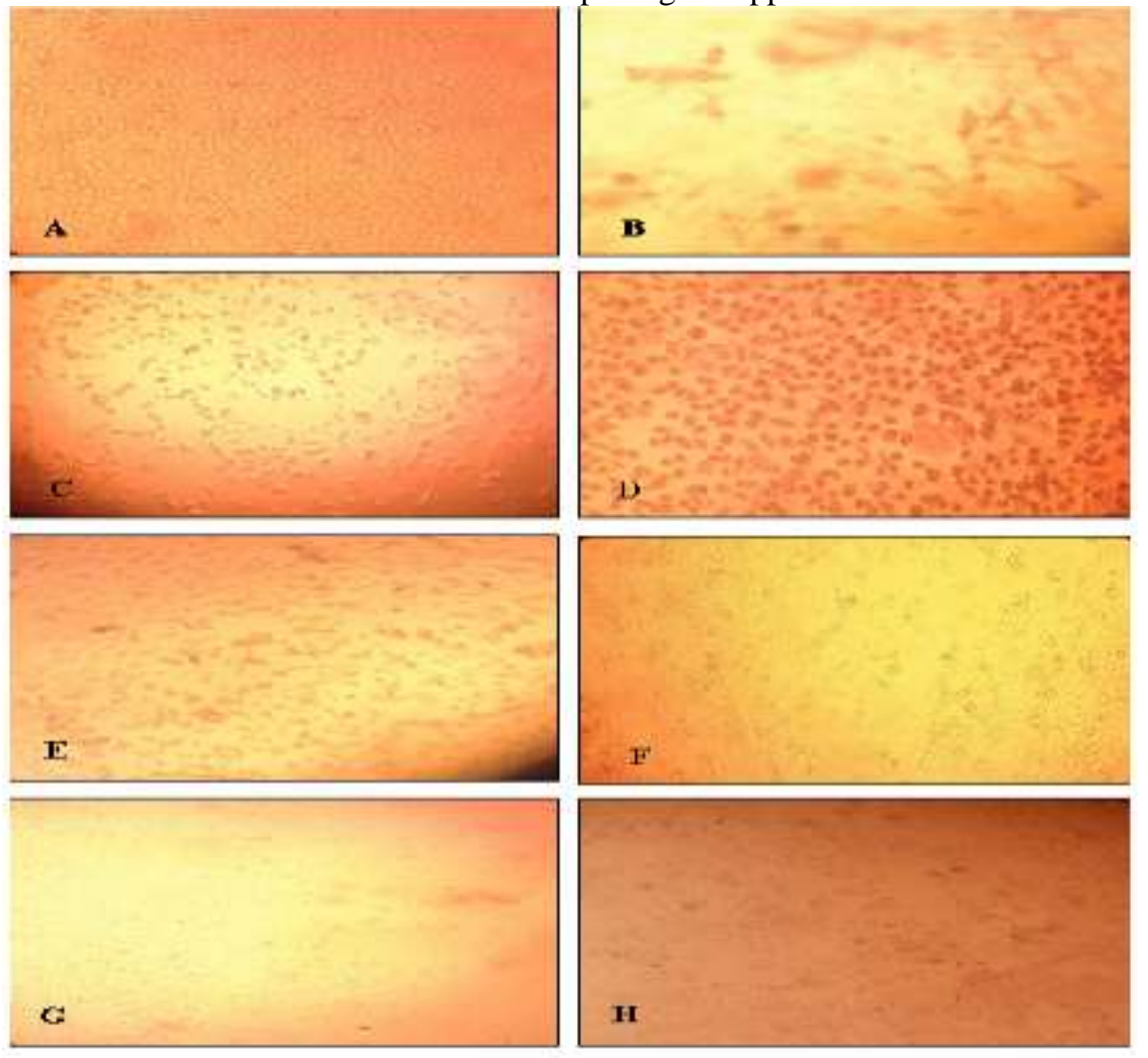

Figure (12):- Morphological characteristics of unstained treated and untreated $\mathbf{C a C o 2}$ cells: (A): untreated cells, showed the given growth during the period of experiment, (B): Cells treated with $(400,200,100,50 \& 25 \mu \mathrm{g} / \mathrm{ml})$ of bee venom. (C): Cells treated with $12.5 \mu \mathrm{g} / \mathrm{ml}$ of bee venom. (D): Cells treated with $6.25 \mu \mathrm{g} / \mathrm{ml}$ of bee venom. (E): Cells treated with $(1 \& 0.5 \mathrm{mg} / \mathrm{ml})$ of chitosan nanoparticles. (F): Cells treated with $(0.031 \mathrm{mg} / \mathrm{ml})$ of chitosan nanoparticles. (G): Cells treated with $(300,150,75,37.5 \& 18.75 \mu \mathrm{g} / \mathrm{ml})$ of bee venom loaded chitosan nanoparticles. $(\mathbf{H})$ : Cells treated with $(9.37 \mu \mathrm{g} / \mathrm{ml})$ of bee venom loaded chitosan nanoparticles $(10 \mathrm{X})$.

\section{Discussion:-}

Although it has been previously reported that bee venom had inhibitory effect on many cancer cell lines such as hepatocellular carcinoma, breast cancer, prostate cancer, ovarian and colon cancer cell lines (Wang et al., 2009; Ip et al., 2008; Park et al., 2011; Jo et al., 2012 and Zheng et al., 2015), there is no study on the effect of bee venom when loaded on the nanoparticles for any cancer cell line. The current study was designed to prepare bee venom loaded chitosan NPs and investigated their ability to inhibit proliferation of cancer cells with the aim of increasing the related drug anticancer properties as well as reducing their systemic side-effects based on the demonstrated phenomena in cancerous tissues which is the preferably accumulation of macromolecules in tumor tissue due to increased permeability of tumor vascular network in the absence of lymphatic clearing system.( Sayari et al., 2014;

Goodarzi et al., 2014 and Dinarvand et al., 2011). Extraction of chitosan from shrimp exoskeletons requires harsh chemical treatments. The shrimp exoskeletons even though contains majority of chitin, also has proteins and minerals. Proteins are removed by deproteinization while carbon and other salts are removed by demineralization. Chitin is a linear polymer of 2-acetamido-2-deoxy- $\beta$-D-gluco-pyranose (Glc NAc) which is deacetylated to form chitosan. It is a linear binary polymer of Glc NAc and 2-amino-2- deoxy- $\beta$-D-gluco-pyranose (Glc N) (Badawy and Rabea, 2011). The Preconditioning method of chitosan extraction is superior to other available methods based on 
the higher yield of pure quality chitosan. All deproteinization and demineralization steps were repeated twice. This induced a higher yield of chitin from the shells. The final deacetylation of chitin at $100{ }^{\circ} \mathrm{C}$ for 5 hours gave a longer reaction time which resulted in higher yield of chitosan. The chitosan yield from the chitin of abdominal exoskeleton and carapaces were found to be 54.94\% and 59.6\%. Sewvandi and Adikary, 2012 extracted chitosan (55.8\%) from Penaeus monodon shrimp shells by the Preconditioning method. Also, Kamala et al., (2013) recorded 54.31\% chitosan yield from Penaeus stylifera shrimp shell. Other authors extracted chitosan from other shrimp species with different yield percentages such as Puvvada $\boldsymbol{e t}$ al., 2012 and Divya $\boldsymbol{e t}$ al., 2014. The difference in chitosan yield may be due to the differences in reaction time, steps of chemical extraction and the part of exoskeleton taken in procedure (Yen et al., 2009). Quality of chitosan is mainly determined by the degree of deacetylation, which depends on the materials and conditions of processing (Suhardi, 1993). Degree of deacetylation affects thechemical, physical and biological properties of chitosan, such as adsorption, covalent linking, encapsulation and plays a significant role for determining the specific applications of chitosan. Li et al., 1997; Muzzarelli, 1985 suggested that the term chitosan should be used when the degree of deacetylation is above $70 \%$. The deacetylation degree of chitosan was $80.29 \%$ for abdominal skeleton and $84.71 \%$ for carapaces.based on different parts of shrimp exoskeletons, which was achived in the present work that our results agreed with those obtained by (Divya $\boldsymbol{e t}$ al., 2014) who found that Degree of deacetylation of chitosan extracted from Penaeus monodon shrimp recorded $85 \%$. Also, (Patria, 2013) showed that Deacetylation degree of chitosan obtained from Penaeus monodon shrimp ranged from 76.26 to $91.60 \%$ with average overall deacetylation degree was $82.86 \%$. Other author recorded low degree of deacetylation such as Sewvandi and Adikary, (2012) who found Deacetylation degree of chitosan obtained from Penaeus monodon shrimp ranged from $48.5 \%$ to $54.4 \%$. The solubility of chitosan in acetic acid is a mark of its purity. Proportionally increase in solubility was observed with increasing deacetylation degree. This is due to the acetyl group removal in chitin deacetylation process which is cut by leaving amine group. Presence of carboxyl group in acetic acid would facilitate the dissolution of chitosan due to the hydrogen interaction between the carboxyl and the amine group of chitosan (Li et al., 1997). The solubility percentage in the present study of chitosan obtained from abdominal skeletons and carapaces were 91.17 and $100 \%$, respectively. An increase in the solubility was observed with increasing deacetylation degree. Brine and Austin (1981) suggested that lower solubility values due to incomplete removal of protein and acetyl group, therefore the lower DD value could adversely interfere with the solubility degree. Some authors recorded other solubility percentage such as Patria, (2013) who found that the solubility of chitosan extracted from Penaeus monodon shrimp was ranged from $17.43 \%$ to $95.29 \%$ with average of 57.52 \% and Hossain and Iqbal (2014) who recorded that the solubility of chitosan obtained from shrimp waste was ranged from $48.3 \%$ to $97.65 \%$. From the obtained results it was proved that the chitosan obtained from carapaces of Penaeus karatherus has a higher yield, deacetylation degree and solubility than that of abdominal skeletons, so this chitosan sample was regarded as the optimum one and used in the rest of the experiments in this work. The structure of the extracted chitosan was confirmed by FTIR analysis. The major absorption band was observed at peak $1033 \mathrm{~cm}-1$ which represents the free amino group (-NH2) at C2 position of glucosamine, a major group present in chitosan. Further the sample showed the absorption bands for the free amino group between 1026 and $1259 \mathrm{~cm}-1$ when the peak at $1374 \mathrm{~cm}-1$ represents the $-\mathrm{C}-\mathrm{O}$ stretching of primary alcoholic group (-CH2 - OH). The absorbance bands of 3268, 2930,2878,1563, and $1418 \mathrm{~cm}-1$ indicated the N-H stretching, Symmetric CH3 stretching and asymmetric $\mathrm{CH} 2$ stretching, $\mathrm{CH}$ stretching, $\mathrm{C}=\mathrm{O}$ stretching in secondary amide (amide $\mathrm{I}$ ) and $\mathrm{C}-\mathrm{N}-$ stretching in secondary amide (amide II), respective-ly. In the present study also the same absorbance bands were observed at 3283, 2921, 2865,1643,1552,1421, 1022, 893and $752 \mathrm{~cm}-1$ which confirms the structure of chitosan. The results were in accordance with Kucukgulmez et al., (2011) who extracted chitosan from Metapenaeus stebbingi shrimp shells, Kamala et al (2013) who prepared and characterized water soluble chitosan from Parapeneopsis stylifera shrimp shells and Hajji et al., (2015) characterized chitosan which was extracted from three Tunisian marine sources shrimp (Penaeus kerathurus) waste, crab (Carcinus mediterraneus) shells and cuttlefish (Sepia officinalis) bones. Intrinsic viscosity is an important rheological parameter which is used to characterize the hydrodynamic properties of polymers. The viscosity of the pharmaceutical chitosan is very important aspect in handling as polymer for the drug delivery. Also viscosity is an important factor in the conventional determination of molecular weight of chitosan by use of the Mark-Houwink's equation (Wang et al., 1991). Higher molecular weight chitosan often provide highly viscous solutions, which may not be desirable for industrial handling. Hence chitosan of low viscosity is more preferred (Badawy and Rabea, 2011). The viscosity profile of the prepared chitosan was $147.6 \mathrm{cps}$ fall under the region of the most pharmaceutical products do which are suitable for designing drug delivery systems Puvvada et al., 2012. The molecular weight of the obtained chitosan in this study was 1152693.47Da, which is compatible with the commercial chitosan products that have molecular weight range from 100,000 to 1,200,000 Daltons (Li et al., 1992). Puvvada et al., 2012 determined the viscosity and molecular weight of Penaeus monodon shrimp chitosan (304 cps and 1,599,558.029 Da, respectively). Also, (Divya et al., 2014) 
measured the viscosity in chitosan obtained from Penaeus monodon shrimp ( $80 \mathrm{cps}$ ). The Ash measurement is an indicator of the effectiveness of the demineralization step for removal of calcium carbonate. Some residual ash of chitosan may affect their solubility, consequently contributing to lower viscosity, or can affect other more important characteristics of the final product (No and Lee , 1995). A high quality grade of chitosan should have less than $1 \%$ of ash content. Ash value of chitosan obtained in this study was $0.4 \%$. The results show similarities with ash contents (0.59-0.61\%) of chitosan obtained from Metapenaeus stebbingi shells (Kucukgulmez et al., 2011). The A. mellifera venom was loaded on nanoparticles with success. The encapsulation efficiency increased from $86 \%$ to $96.5 \%$ and loading capacity also increased from $0.81 \%$ to $45.54 \%$ as the concentration of venom increased. This high level of encapsulation efficiency can be explained by that, the venom was dissolved in TTP solution at the moment of cross-linked nanoparticle formation, these protein molecules are completely trapped inside the polymeric matrix of chitosan nanoparticles (Gan and Wang, 2007). Moreover, the electrostatic interactions between positively charged groups of chitosan and negatively charged proteins are frequent during the formation of nanoparticles and other parts adsorbed on the surface of nanoparticles (Gan et al., 2005). Optimum loading capacity and encapsulating efficiency were obtained with venom concentration of $500 \mu \mathrm{g} / \mathrm{ml}$. Several authors evaluated the encapsulating efficiency and loading capacity of animal venoms loaded on chitosan nanoparticles such as Rocha Soares $\boldsymbol{e t}$ al., (2012) who recorded a high value of encapsulation efficiency that greater than $90 \%$ for Tityus serrulatus scorpion venom loaded on chitosan nanoparticles.

These interactions between chitosan nanoparticles and bee venom were confirmed by several parameters including the morphological characteristic of nanoparticles which were observed by using high resolution Transmission electron microscopy. Results in the present study showed that the spherical shape nanoparticles were formed in both free chitosan nanoparticles and bee venom loaded chitosan nanoparticles, but in bee venom loaded ones there was a layer around the nanoparticle core. This layer was due to bee venom adsorbed on the surface of nanoparticles and increased the hydrodynamic size of the nanoparticles. The results were in accordance with Dounighi $\boldsymbol{e t}$ al., (2010), Mohammadpourdounighi et al (2012a) and Dounighi et al (2012b) who observed that the shape of the nanoparticles was approximate to spheres with almost homogeneous structure when Naja oxiana snake venom, Mesobuthus eupeus scorpion venom and Hemiscorpius lepturus Scorpion venom loaded on chitosan nanoparticles.

The DLS analysis revealed that by increasing the chitosan concentration gradually from 1 to $5 \mathrm{mg} / \mathrm{mL}$ at a constant TPP concentration, the size of nanoparticles increased. The PDI value of nanoparticles with chitosan concentration of $1 \mathrm{mg} / \mathrm{mL}$ and $2 \mathrm{mg} / \mathrm{ml}$ was within the acceptable range that less than 0.5 . However, according to the reports on the effect of chitosan/TPP mass ratio on encapsulating efficiency and protein release profiles, it can be concluded that a lower chitosan/TPP ratio produces higher overall release and protein encapsulation (Gan $\boldsymbol{e t}$ al., 2005). It has been explained that a lower viscosity of the gelation medium with lower concentration of chitosan results in a decrease in the liquid phase resistance against dispersion, forming smaller nanoparticles and further promoting protein encapsulation. (Wu et al., 2005 and Zhang $\boldsymbol{e t}$ al., 2010). Therefore, we suggested that $1 \mathrm{mg} / \mathrm{mL}$ of chitosan and 1 $\mathrm{mg} / \mathrm{mL}$ TPP concentration are suitable for venom loading. The above mentioned results agreed with those obtained by Dounighi et al., (2012a) and Dounighi et al., (2015) who reported that average size, measured by Zetasizer, Mesobuthus eupeus scorpion venom-loaded nanoparticles and Echis carinataus snake venom loaded nanoparticles were larger than chitosan nanoparticles. In contrast, Rocha Soares et al (2012) found that size Tityus serrulatus scorpion venom loaded nanoparticles was smaller than chitosan nanoparticles. Zeta potential is quite important for colloids and nanoparticles in suspension. Its value is closely related to suspension stability and particle surface morphology (Mohanraj and Chen, 2006). Zeta potential of the chitosan loaded nanoparticles can greatly influence their stability in media through electrostatic repulsion between the particles. The present results indicated that zeta potential analysis, in which the protein was, added leads to a decrease in the positive charge on the particle surface from $43.7 \mathrm{mV}$ of the nanoparticles only to $36.1 \mathrm{mV}$ by loading the bee venom. This reduction can be due to interaction of the venom with polymer and molecules of venom adsorbed on the surface of the particles (Gan and Wang, 2007). The carboxyl groups on the surface of a large protein molecule may form hydrogen bond with amine groups at certain sites at the spread chitosan chain but, still maintaining a compact 3-D structure without spreading at the solution $\mathrm{pH}$ condition $(\mathrm{pH} 4.7)$ so as to keep an inner hydrophobic core. Therefore, protein molecule attachment did not sufficiently suppress the positive surface charge of chitosan molecules, when the z-potential profile of chitosan NPs is compared with the z-potential of CS NPs containing bee venom. It still seems that a high proportion of free amine groups on the chitosan chain remained unoccupied. Similar results were obtained by Rocha Soares et al., (2012) who found that the zeta potential decreased from $42.37 \mathrm{mV}$ to $24.34 \mathrm{mV}$ after loading Tityus serrulatus scorpion venom on chitosan. Also, Dounighi et al., (2012a) demonstrated that the zeta potential of 
chitosan nanoparticles only and Mesobuthus eupeus scorpion venom loaded nanoparticles were $50.3 \mathrm{mV}$ and 44.1 $\mathrm{mV}$, respectively.

During stability studies of nanoparticles, it was noticed that the bee venom loaded chitosan nanoparticles were stable at room temperature and showed the same efficiency after two and four months of storing at room temperature as compared with zero time. The stability of the venom during encapsulation and storage of venom loaded nanoparticles is very important technical concept. These results are similar to that of Bhowmik et al., (2013) who observed that the gold nanoparticles conjugated with protein toxin (NKCT1) isolated from Indian cobra Naja kaouthia is stable at room temperature and showed the same efficiency effect after 1 month of storing at room temperature. In the present study the FTIR spectrum of chitosan nanoparticles was different from the chitosan matrix that, in the chitosan nanoparticles peak of $3433 \mathrm{~cm}^{-1}$ becomes wider, which indicating that hydrogen bonding was enhanced (Wu et al 2005) and the $1643 \mathrm{~cm}^{-1}$ peak of $-\mathrm{NH} 2$ bending vibration shifted to $1537 \mathrm{~cm}-1$ and a new sharp peak $1641 \mathrm{~cm}-1$ appeared. The FTIR spectrum of chitosan nanoparticles was consistent due to chitosan film modified by phosphate, and it could be attributed to linkage between phosphoric and ammonium ion. The ammonium groups of chitosan are linked with tripolyphosphoric groups of TPP in nanoparticles. Moreover, no difference was observed between bee venom loaded chitosan nanoparticles with free chitosan nanoparticles. The findings of this work were in agreement with the studies carried out by Lam et al. 2006, Rocha Soares et al 2012, Dounighi et al 2012 and Dounighi et al (2015) who found that the $1654 \mathrm{~cm}-1$ peak of $\mathrm{N}-\mathrm{H}$ bonding vibration shifted to $1540 \mathrm{~cm}^{-1}$ and a new sharp peak $1635 \mathrm{~cm}^{-1}$ appeared in CS/TPP nanoparticles after addition of TPP. This study revealed that there were possibilities to modulate the release rate of bee venom from chitosan nanoparticles by adjusting the concentration of bee venom. The in vitro release profile of venom nanoparticles showed that in the first $6 \mathrm{hrs}$ of incubation about 50\% of the venom released followed by a slow release of 35\% for the subsequent $42 \mathrm{hrs}$. Some reports on microspheres showed that the release process involved two different mechanisms that were the diffusion of protein molecules and degradation of polymer matrix. Initial burst release of the venom was due to the venom molecules dispersing close to the nanoparticles surface, which easily diffuse in the initial incubation time. Followed by sustained release phase was due to the slow degradation of nanoparticles leading to the release of entrapped venom with a constant rate (Zhou and Li 2001, Zhou et al., 2004 and Zhou $e t$ al., 2002). Our results agreed with Dounighi et al (2012a) and Dounighi et al., (2015) who recorded the release of Mesobuthus eupeus scorpion venom-loaded nanoparticles and Echis carinataus snake venom loaded nanoparticles in PBS. The release profile of venom loaded nanoparticles exhibits an initial burst release of in the first 10 hours followed by a slow release for the subsequent the hours. Initial release of the venom is due to the venom molecules dispersing close to the nanoparticles surface, which easily diffuse in the initial incubation time. The release profile was characterized by an initial burst effect, followed by a continuous and sustained release phase. In the present study, the inhibitory effect of bee venom was observed on the growth of colon cancer $(\mathrm{CaCo} 2)$ using MTT assay. Also the effectiveness of venom loaded chitosan nanoparticles as anticancer drug which exceeded the anticancer effect of the bee venom alone was recorded. Competency of drug-loaded nanoparticles in inhibiting the growth of leukemic cells (U937 and K562) cells were recently studied by Bhowmik and Saha (2013), where gold nanoparticles (GNPs) conjugated with a protein toxin from the Indian cobra Naja kaouthia venom (NKCT1) were used to targeted leukemia cells more profoundly than native NKCT1. Similar observation was also recorded by Luo et al., (2009) and Yang et al., (2009) who have used N succinyl chitosan nanoparticles and lipid nanoparticles on K562 cells for better antitumor effect. The lower uptake of bee venom is attributed to the resistance experienced by them due to P-gp pump highly expressed on cancer cells (Hui et al. 2008) which acts as an energy drug efflux pump and leads to decrease in cytotoxic protein accumulation. The nanoparticles conjugation system escapes the Pgp pump as their uptake is mediated by specific endocytic processes (Sahoo and Labhasetwar 2005). Thus, Chitosan nanoparticles-conjugated bee venom preferentially delivered into the nucleus inside the cells for eliciting a better therapeutic effect than native bee venom, where chitosan able to escape the endosomes offering high potential for nuclear delivery. Molecular entry into the nucleus occurs through the nuclear pore complexes; the efficiency of which is dependent on NP size and the presence of nuclear localization sequence (NLS) (Tammam et al., 2015).

\section{References:-}

1. Badawy, M.E.I. and Rabea, E.I. (2011): A biopolymer chitosan and its derivatives as promising antimicrobial agents against plant pathogens and their applications in crop protection. International Journal of Carbohydrate Chemistry, 2011: 1-29.

2. Bagheri-Khoulenjani, S. ; Taghizadeh, S. M. and Mirzadeh, H. (2009): An investigation on the short-term biodegradability of chitosan with various molecular weights and degrees of deacetylation. Carbohydrate Polymers, 78 (4): 773-778. 
3. Baxter, A.; Dillon, M.; Anthony Taylor, K. D. and Roberts, G. A. F. (1992): Improved method for i.r. determination of the degree of N-acetylation of chitosan. International Journal of Biological Macromolecules, 14 (3): 166-169.

4. Bhowmik,T. ; Saha,P. P.; Dasgupta, A. and Gomes, A. (2013): Antileukemic potential of PEGylated gold nanoparticle conjugated with protein toxin (NKCT1) isolated from Indian cobra (Naja kaouthia) venom. Cancer Nano, 4:39-55.

5. Bradford, M. (1976): A Rapid and sensitive method for the quantitation of microgram quantities of protein utilizing the principle of protein-dye binding. Anal Biochem. 72: 248-54.

6. Brine, C.J. and Austin, P.R. (1981): Chitin variability with species and method of preparation. Comp. Biochem. Physiol. 69B: 283-286.

7. Delorino, M.A. and Cresidio, S.P. (2009): Investigation of chitosan from squid pen as Scar Remover. World Appl. Sci. J., 5: 98-103.

8. Dinarvand, R.; Sepehri, N.; Manoochehri, S.; Rouhani, H. and Atyabi, F. (2011): Polylactide-co-glycolide nanoparticles for controlled delivery of anticancer agents. Int. J. Nanomedicine , $6: 877-895$.

9. Divya, K.; Rebello, S. and Jisha M. S. (2014): A Simple and Effective Method for Extraction of High Purity Chitosan from Shrimp Shell Waste. Proc. of the Intl. Conf. on Advances In Applied Science and Environmental Engineering, 141-145.

10. Dounighi, M.N.; Behfar, A.; Ezabadi, A.; Zolfagharian, H. and Heydari, M. (2010): Preparation of chitosan nanoparticles containing Naja naja oxiana snake venom. Nanomedicine: Nanotechnology, Biology and Medicine 6(1):137-43.

11. Dounighi, N.; Eskandari, R.; Avadi, M.R.; Zolfagharian, H.; Mir Mohammad Sadeghi, A. and Rezayat, M. (2012a): Preparation and in vitro characterization of chitosan nanoparticles containing Mesobuthus eupeus scorpion venom as an antigen delivery system. The Journal of Venomous Animals and Toxins including Tropical Diseases, 18 (1): 44-52.

12. Dounighi, N.; Damavandi, M. ; Zolfagharian, H. and Moradi, S.(2012b): Preparing and Characterizing Chitosan Nanoparticles Containing Hemiscorpius lepturus Scorpion Venom as an Antigen Delivery System. Archives of Razi Institute, 67 (2): 145-153.

13. Dounighi, N.; Mehrabi, M.; Avadi, M.R.; Zolfagharian, H. and Rezayat, M. (2015): Preparation, characterization and stability investigation of chitosan nanoparticles loaded with the Echis carinatus snake venom as a novel delivery system. Archives of Razi Institute, 70 (4):269-277.

14. Faraji, AH and Wipf, P. (2009): Nanoparticles in cellular drug delivery. Bioorg Med Chem 17:2950-2962

15. Gan, Q.; Wang, T.; Cochrane, C. and McCarron, P. (2005): Modulation of surface charge, particle size and morphological properties of chitosan-TPP nanoparticles intended for gene delivery. Colloids Surfaces B., 44(23):65-73.

16. Gan, Q. and Wang, T. (2007): Chitosan nanoparticles as protein delivery carrier-systematic examination of fabrication conditions for efficient loading and release. Colloids Surfaces B., 59(1):24-34.

17. Gerlier, D. and Thomasset, N. (1986). Use of MTT colorimetric assay to measure cell activation. J. Immunol. methods, 94(1-2): 57- 63.

18. Ghosh, P.; Han, G.; De, M.; Kim, C.K. and Rotello, V.M. (2008): Gold nanoparticles in delivery applications. Adv Drug Deliver Rev 60:1307-1315

19. Goodarzi, N.; Ghahremani, M. H. ; Amini, M.; Atyabi, F.; Ostad, S. N. ; Shabani Ravari, N.; Nateghian, N. and Dinarvand, R.(2014): CD44-targeted docetaxel conjugate for cancer cells and cancer stem-like cells: a novel hyaluronic acid-based drug delivery system.Chem. Biol. Drug Des., 83(6):741-752.

20. Hajji, S.; Younes, I.; Rinaudo, M.; Jellouli, K.and Nasri, M. (2015): Characterization and In Vitro Evaluation of Cytotoxicity, Antimicrobial and Antioxidant Activities of Chitosans Extracted from Three Different Marine Sources. Appl Biochem Biotechnol, 177(1): 18-35.

21. Hejazi, R. and Amiji, M. (2003): Chitosan-based gastrointestinal delivery systems. Journal of Controlled Release 89: 1-165.

22. Hossain, M. S. and Iqbal, A. (2014): Production and characterization of chitosan from shrimp waste. J. Bangladesh Agril. Univ. 12(1): 153-160.

23. Hu, C.M.J. and Zhang, L. (2012): Nanoparticle-based combination therapy toward overcoming drug resistance in cancer. Biochem Pharmacol 83:1104-1111

24. Hui, R.C.; Francis, R.E.; Guest, S.K.; Costa, J.R.; Gomes, A.S.; Myatt, S.S. et al (2008): Doxorubicin activates FOXO3a to induce the expression of multidrug resistance gene ABCB1 (MDR1) in K562 leukemic cells. Mol Cancer Ther 7:670-678. 
25. Ip, S.W.; Chu, Y.L.; Yu, C.S.; Chen, P.Y.; Ho, H.C.; Yang, J.S.; Huang, H.Y.; Chueh, F.S.; Lai, T.Y. and Chung, J.G. (2012): Bee venom induces apoptosis through intracellular Ca2+ -modulated intrinsic death pathway in human bladder cancer cells. International journal of urology: official journal of the Japanese Urological Association. 19:61-70.

26. Ip, S.W.; Liao, S.S.; Lin, S.Y.; Lin, J.P.; Yang, J.S.; Lin, M.L.; Chen, G.W.;Lu, H.F.; Janakiram, N.B. and Rao, C.V. (2014): The role of inflammation in colon cancer. Adv Exp Med Biol. 816:25-52.

27. Jo, M.; Park, M.H.; Kollipara, P.S., An, B.J.; Song, H.S., Han, S.B.; Kim, J.H.; Song, M.J. and Hong, J.T. (2012): Anti-cancer effect of bee venom toxin and melittin in ovarian cancer cells through induction of death receptors and inhibition of JAK2/STAT3 pathway. Toxicology and applied pharmacology. 258:72-81.

28. Kamala, K. ; Sivaperumal, P. and Rajaram, R. (2013): Extraction and Characterization of Water Soluble Chitosan from Parapeneopsis Stylifera Shrimp Shell Waste and Its Antibacterial Activity. International Journal of Scientific and Research Publications, 3 (4): 1-8.

29. Kucukgulmez, A.; Celik, M.; Yanar, Y; Sen, D. ; Polat, H. and Kadak, A.E. (2011): Physicochemical characterization of chitosan extracted from Metapenaeus stebbingi shells. Food Chemistry 126: 1144-1148

30. Lam, T.D.; Hoang, V.D.; Lien, L.N.; Thinh, N.N. and Dien, P.G. (2006): Synthesis and characterization of chitosan nanoparticles used as drug. J Chem, 44:105-109.

31. Li, Q.; Dunn, E.T.; Grandmaison, E.W. and Goosen, M. F. A. (1997): Applications and properties of chitosan. In: Applications of chitin and chitosan. Goosen M. F. A. (ed), pp. 3-29,Technomic Publishing Company, Lancaster.

32. Li, Q.; Dunn, E.T.; Grandmaison, E.W. and Goosen, M.F.A. (1992): Applications and properties of chitosan. Journal of Bioactive Compatible Polymers, 7, 370-397.

33. Lin, M.W.; Han, S.M. and Chung, J.G. (2008): The role of mitochondria in bee venom-induced apoptosis in human breast cancer MCF7 cells. In Vivo, 22(2):237-245.

34. Long, J.H.W.S. (2013): Synthesis and characterization of chitosan from shrimp shells. A project report submitted in partial fulfilment of the requirements for the award of Bachelor of Engineering (Hons.) Faculty of Engineering and Science Universiti Tunku Abdul Rahman.

35. Luo, H.; Li, J. and Chen, X. (2009): Antitumor effect of N-succinyl-chitosan nanoparticles on K562 cells. Biomedecine \& pharmacotherapy, 64(8):521-526.

36. Mohanraj, V.J and Chen, Y (2006): Nanoparticles - A Review. Tropical Journal of Pharmaceutical Research, 5 (1): 561-573.

37. Monarul, I.Md.; Masum, S.Md.; Mahbubur, R.M.; Md. Ashraful Islam, M.Md.; Shaikh, A.A. and Roy, S.K. (2011): Preparation of Chitosan from Shrimp Shell and Investigationof Its Prop-erties. International Journal of Basic \& Applied Sciences, 11(1): 116-130.

38. Moon, D.O.; Park, S.Y.; Heo, M.S.; Kim, K.C.; Park, C.; Ko, W.S.; Choi, Y.H. and Kim, G.Y.(2006): Key regulators in bee venom-induced apoptosis are Bcl-2 and caspase-3 in human leukemic U937 cells through downregulation of ERK and Akt. International immunopharmacology. 6:1796-1807.

39. Muzzarelli, R. A. A. (1985): Chitin. In: "The polysaccharides" (G.O. Aspinall, ed), 3: 417- 450. Academic Press, New York.

40. No, H.K. and Lee, M.Y. (1995): Isolation of Chitin from Crab Shell Waste. Journal Korean Soc. Food Nutrition, 24(1):105-113.

41. Park, H.J.; Son, D.J.; Lee, C.W.; Choi, M.S.; Lee, U.S.; Song, H.S.; Lee, J.M. and Hong, J.T. (2007): Melittin inhibits inflammatory target gene expression and mediator generation via interaction with IkappaB kinase. Biochemical pharmacology. 73:237-247.

42. Park, M.H.; Choi, M.S.; Kwak, D.H.; Oh, K.W.; Yoon, D.Y.; Han, S.B.; Song, H.S.; Song, M.J. and Hong, J.T. (2011): Anti-cancer effect of bee venom in prostate cancer cells through activation of caspase pathway via inactivation of NF-kappaB. The Prostate. 71:801-812.

43. Patria, A. (2013): Production and characterization of Chitosan from shrimp shells waste. AACL Bioflux, 6 (4): 339-344.

44. Putz, T.; Ramoner, R.; Gander, H.,; Rahm, A.; Bartsch, G.; Bernardo, K.; Ramsay, S. and Thurnher, M. (2007): Bee venom secretory phospholipase A2 and phosphatidylinositol-homologues cooperatively disrupt membrane integrity, abrogate signal transduction and inhibit proliferation of renal cancer cells. Cancer immunology, immunotherapy: CII. 56:627-640.

45. Puvvada,Y.S. ; Vankayalapati, S. and Sukhavasi, S. (2012): Extraction of chitin from chitosan from exoskeleton of shrimp for application in the pharmaceutical industry. International Current Pharmaceutical Journal, 1(9): 258-263. 
46. Rocha Soares, K.S.; Cardozo Fonseca, J.L.; Oliveira Bitencourt, M.A.; Santos, K.S.C.R.; Silva-Júnior, A.A. and Fernandes-Pedrosa, M.F. (2012): Serum production against Tityus serrulatus scorpion venom using cross-linked chitosan nanoparticles as immunoadjuvant. Toxicon 60: 1349-1354.

47. Sahoo, S.K. and Labhasetwar, V. (2005): Enhanced anti-proliferative activity of transferring conjugated paclitaxel loaded nanoparticle is mediated via sustained intracellular drug retention. Mol Pharm 2:373-383.

48. Sayari, E.; Dinarvand, M.; Amini, M.; Azhdarzadeh, M. ; Mollarazi, E.; Ghasemi, Z. and Atyabi, F. (2014): MUC1 aptamer conjugated to chitosan nanoparticles, an efficient targeted carrier designed for anticancer SN38 delivery. Int. J. Pharm., 473(1), 304-315.

49. Sewvandi, G.A. and Adikary, S.U. (2012): Synthesizing and Characterization of Natural Biopolymer Chitosan Derived from Shrimp Type, Penaeus monodon. Tropical Agricultural Research, 23 (3): 272 -276.

50. Son, D.J.; Lee, J.W.; Lee, Y.H.; Song, H.S.; Lee, C.K. and Hong, J.T. (2007): Therapeutic application of anti-arthritis, pain-releasing, and anti-cancer effects of bee venom and its constituent compounds. Pharmacology \& therapeutics. 115:246-270.

51. Suhardi (1993): Khitin dan Kitosan. Buku Monograf, Pusat Antar Universitas Pangan dan Gizi UGM, Yogyakarta, 272-278.

52. Swiderska, M.; Choromanska, B.; Dabrowska, E.; Konarzewska- Duchnowska, E.; Choromanska, K.; Szczurko, G.; Mysliwiec, P.; Dadan, J.; Ladny, J.R. and Zwierz, K. (2014): The diagnostics of colorectal cancer. Contemp Oncol (Pozn). 18:1-6.

53. Tammam, S.N.; Azzazy, H.M.E.; Breitinger, H.G. and Lamprecht, A. (2015): Chitosan Nanoparticles for Nuclear Targeting; the Effect of Nanoparticle Size and Nuclear Localization Sequence Density. Molecular Pharmaceutics, 1155: 1-23.

54. Tiwari, P.M.; Vig, K.; Dennis, V.A. and Singh, S.R. (2011): Functionalized gold nanoparticles and their biomedical applications. Nanomaterials 1:31-63

55. Venkatesan, C.; Vimal, S. and Sahul Hameed, A. S. (2013): Synthesis and Characterization of Chitosan Tripolyphosphate Nanoparticles and its Encapsulation Efficiency Containing Russell's Viper Snake Venom. J Biochem Moelcular Toxicology, Volume 00, Number 0:1-6.

56. Wang, C.; Chen, T.; Zhang, N.; Yang, M.; Li, B.; Lu, X.; Cao, X. and Ling, C. (2009): Melittin, a major component of bee venom, sensitizes human hepatocellular carcinoma cells to tumor necrosis factor-related apoptosis-inducing ligand (TRAIL)- induced apoptosis by activating CaMKII-TAK1-JNK/p38 and inhibiting IkappaBalpha kinase-NFkappaB. The Journal of biological chemistry, 284: 3804-3813.

57. Wang, W.; Bo, S.Q.; Li, S.Q. and Qin, W. (1991): Determination of the Mark-Houwink equation for chitosans with different degrees of deacetylation. International Journal of Biological Macromolecules, 13: 281285.

58. Wu, Y.; Yang, W.; Wang, C.; Hu, J. and Fu, S. (2005): Chitosan nanoparticles as a novel delivery system for ammonium glycyrrhizinate. Int J Pharm., 295(1-2):235-45.

59. Yacob, N.; Talip, N.; Mahmud, M.; Sani, N.A.I.M.; Samsuddin, N.A. and Fabillah, N.A. (2013): Determination of viscosity-avarage molecular weight of chitosan using intrinsic viscosity measurement. JOURNAL of NUCLEAR and Related TECHNOLOGIES, 10 (1): 39-44.

60. Yang, X.; Koh, C.G.; Liu, S.; Pan, X.; Santhanam, R.; Yu, B. et al (2009): Transferring receptor targeted lipid nanoparticles for delivery of an antisense oligodeoxyribonucleotide against Bcl-2. Mol Pharm, 6:221-230.

61. Yen, M.T.; Yang, J.H. and Mau, J.L. (2009): Physicochemical characterization of chitin and chitosan from crab shells. Carbohydrate polymers, 75(1): 15-21.

62. Zhang, H.L.; Wu, S.H.; Tao, Y.; Zang, L.Q. and Su, Z.Q. (2010): Preparation and characterization of watersoluble chitosan nanoparticles as protein delivery system. J Nanomaterials, 2010: 1-5.

63. Zheng, J.; Lee, H. L.; Ham, Y.W.; Song, H.S.; Song, J. and Hong, J.T. (2015): Anti-cancer effect of bee venom on colon cancer cell growth by activation of death receptors and inhibition of nuclear factor kappa B. Oncotarget, 6, (42): 44437-44451.

64. Zhou, S.; Deng, X.; Yuan, M. and Li, X. (2002): Investigation on preparation and protein release of biodegradable polymer microspheres as Drug-Delivery system. Journal of Applied Polymer Science 84: 778784.

65. Zhou, S.; Liao, X.; Liang, Z.; Li, X.; Deng, X. and Li, H.(2004): Preparation and characterization of biodegradable microspheres containing Hepatitis B surface antigen. Macromolecular Bioscience, 4: 47- 52.

66. Zhou, X.M. and Li, X.H. (2001): Investigation on a novel core-coated microspheres protein delivery system. Journal of Controlled Release 75: 27-36. 